\title{
Implementing Trauma-Informed Care through a Multi-Agency Learning Collaborative: A Theory-Driven Analysis of Outcomes and Sustainability
}

Mira D H Snider M.S.

West Virginia University, mdh0054@mix.wvu.edu

Follow this and additional works at: https://researchrepository.wvu.edu/etd

Part of the Clinical Psychology Commons, and the Health Services Research Commons

\section{Recommended Citation}

Snider, Mira D H M.S., "Implementing Trauma-Informed Care through a Multi-Agency Learning Collaborative: A Theory-Driven Analysis of Outcomes and Sustainability" (2022). Graduate Theses, Dissertations, and Problem Reports. 8339.

https://researchrepository.wvu.edu/etd/8339

This Dissertation is protected by copyright and/or related rights. It has been brought to you by the The Research Repository @ WVU with permission from the rights-holder(s). You are free to use this Dissertation in any way that is permitted by the copyright and related rights legislation that applies to your use. For other uses you must obtain permission from the rights-holder(s) directly, unless additional rights are indicated by a Creative Commons license in the record and/ or on the work itself. This Dissertation has been accepted for inclusion in WVU Graduate Theses, Dissertations, and Problem Reports collection by an authorized administrator of The Research Repository @ WVU.

For more information, please contact researchrepository@mail.wvu.edu. 
Implementing Trauma-Informed Care through a Multi-Agency Learning Collaborative:

A Theory-Driven Analysis of Outcomes and Sustainability

Mira D. H. Snider, M.S.

Dissertation submitted

to the Eberly College of Arts and Sciences

at West Virginia University

in partial fulfillment of the requirements for the degree of

Doctor of Philosophy

in Psychology

Shari A. Steinman, Ph.D., Chair

Amy D. Herschell, Ph.D.

Christina Duncan, Ph.D.

Nicholas Turiano, Ph.D.

John Campo, M.D.

Department of Psychology

Morgantown, West Virginia

2021

Keywords: managed care, learning collaborative, clinical training, trauma-informed care, sustainability, quality improvement

Copyright 2021 Mira D. H. Snider 


\begin{abstract}
Implementing Trauma-Informed Care through a Multi-Agency Learning Collaborative:

A Theory-Driven Analysis of Outcomes and Sustainability
\end{abstract}

Mira D. H. Snider

Learning collaboratives (LCs) are often used in large-scale implementation initiatives to promote evidence-based practice across provider networks. Although the outcomes and stakeholder perspectives of many LCs have been documented, support for the effectiveness of LCs is equivocal, and the means by which LCs achieve long-term improvements in clinical care are not understood. The current study investigated outcomes and sustainability of a multi-agency LC for implementing trauma-informed care in 23 rural Pennsylvania counties. Changes in outcomes (i.e., trauma symptom screening, trauma-informed care training attendance, clinician confidence with using trauma informed-care, utilization of trauma-related diagnostic codes, retention in service, service unit density) were assessed in participating provider agencies $(N=$ 22) over the course of the 15-month LC, and three years after the LC. A theoretical model of clinical training was also applied to determine the extent to which attitude- and skill-related factors were associated with sustained trauma-informed care. Rates of trauma screening, staff training, and high levels of confidence in delivering trauma-informed care increased pre- to postLC. Rates of trauma diagnosis, density of service units received by individuals with trauma, and retention in care for individuals with trauma did not change pre- to post-LC, or during the threeyear sustainment phase. Three years after the LC, trauma symptom screening and staff training improvements were sustained, while staff confidence in delivering trauma-informed care worsened across time. Sustained trauma-informed care behaviors were associated with implementation milestone completion and third-party ratings of quality improvement skills during the LC. Implications of these findings and future directions for research are discussed. 


\section{Acknowledgements}

I would like to thank Dr. Amy Herschell, Shari Hutchinson, and Irina Karpov from the Outcomes Team at Community Care Behavioral Health Organization for supervising my data collection, providing invaluable feedback, and mentoring me during both the conceptualization and completion of this research project. I would also like to thank Dr. Shari Steinman for her mentorship and supervision of my analyses, as well as the other members of my committee: Dr. Duncan, Dr. Turiano, and Dr. Campo for their time and helpful input into this endeavor. Finally, I would like to thank my wonderful husband, family, and friends for their continued support and encouragement throughout my graduate career. 


\section{Table of Contents}

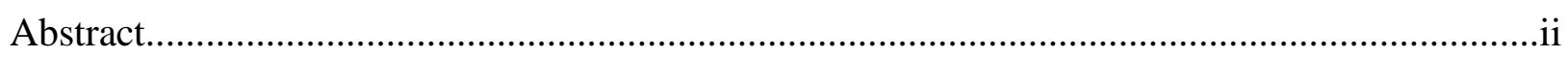

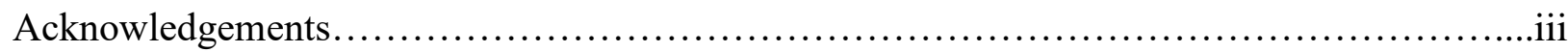

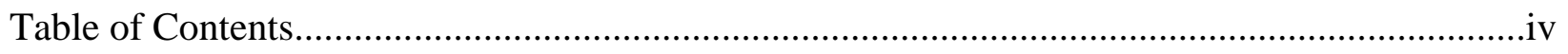

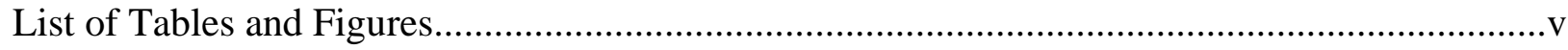

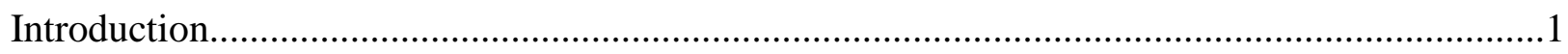

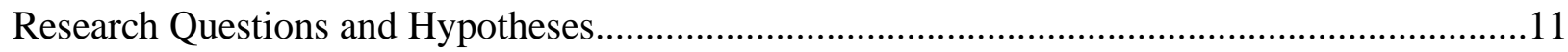

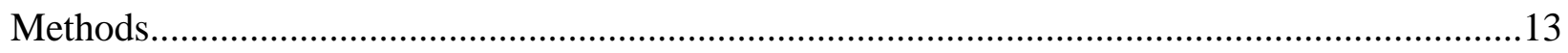

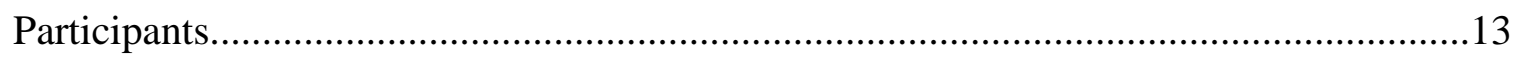

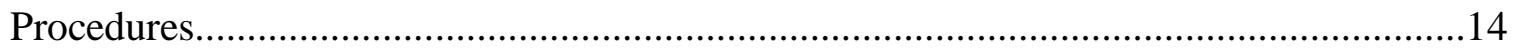

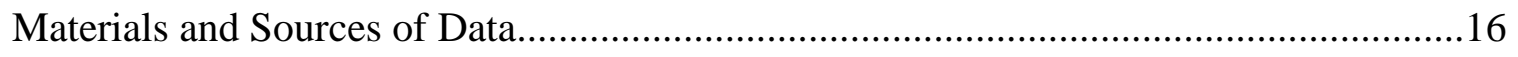

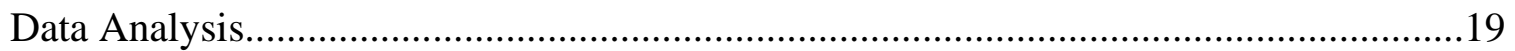

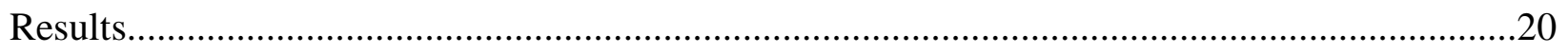

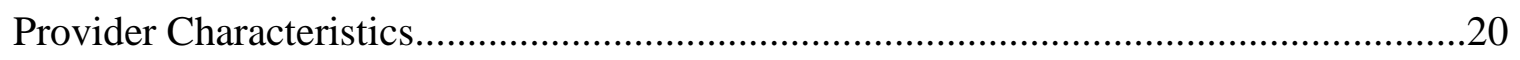

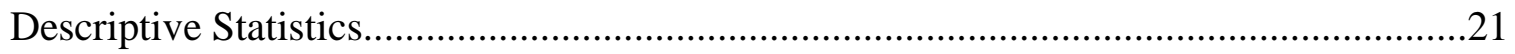

Question 1: Trauma-Informed Care Outcomes...........................................................22

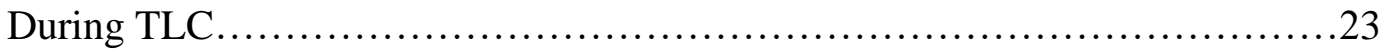

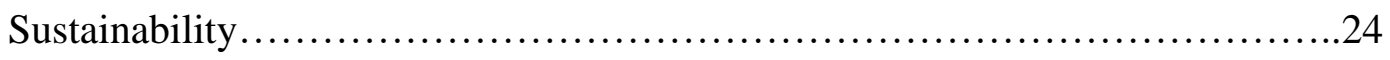

Question 2: Service Outcomes..............................................25

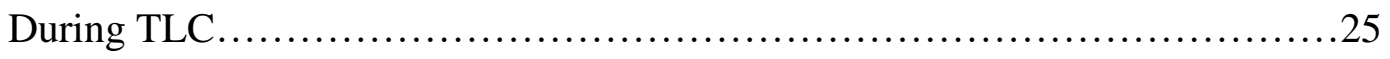

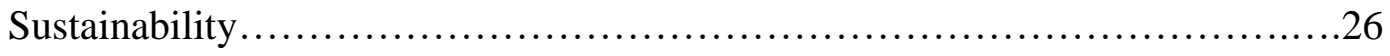

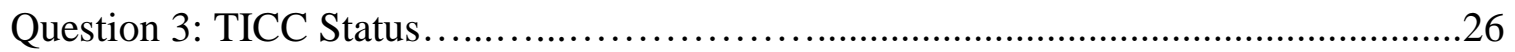

Staff Confidence..................................................27 
TLC Milestones.................................................................27

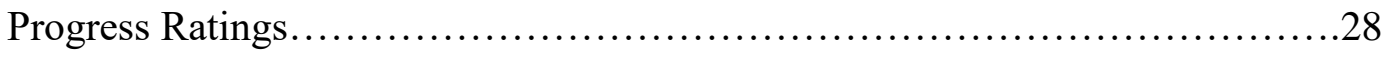

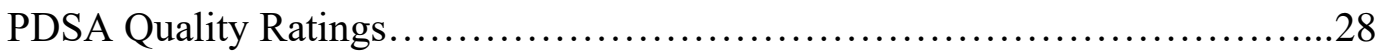

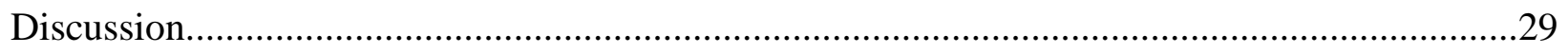

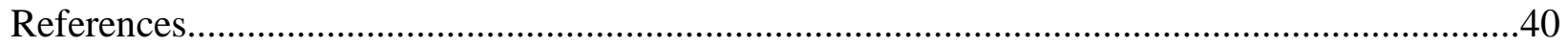

Appendix A: Tables and Figures......................................................................................

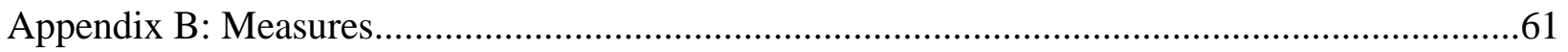

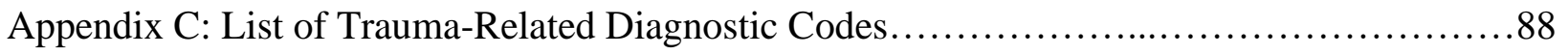

\section{List of Tables and Figures}

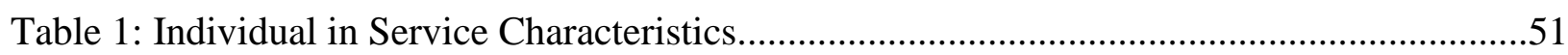

Table 2: Descriptive Statistics of Outcome Variables ..........................................................52

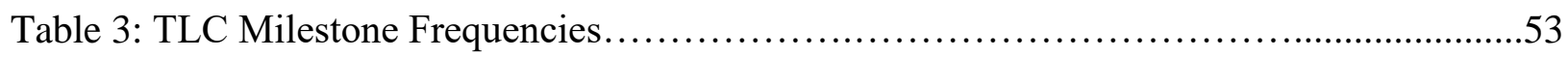

Table 4: TLC PDSA Grade Frequencies...................................................54

Table 5: Correlations Among Outcome Variables ………............................................................55

Table 6: Active Implementation ( $\mathrm{T}_{1}$ to $\left.\mathrm{T}_{15}\right)$ ANOVA Results....................................56

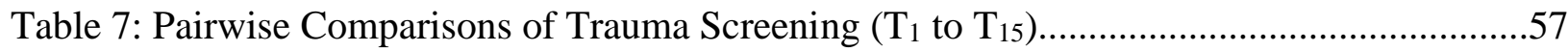

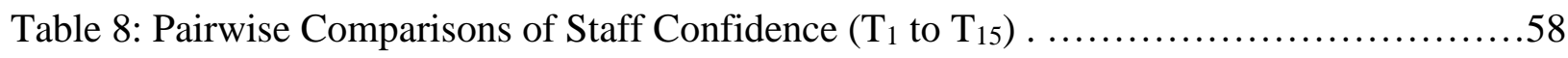

Table 8: Mixed Model Effects for TICC Status in 2018 and 2019........................59

Figure 1: Breakthrough Series Collaborative Model..........................................................60 


\section{Introduction}

Managed care is a common form of health insurance coverage in the United States that is designed to control the cost and quality of healthcare services that are received by consumers. Managed care organizations (MCOs) influence the cost and quality of services by requiring providers to assume financial risk for the cost of care, encouraging consumers to receive care from a specified list of providers, and enforcing quality standards (Enthoven et al., 2019). Multiple types of MCOs exist (e.g., Health Maintenance Organizations, Preferred Provider Organizations, Point of Service), and each type ranges in structural complexity, overhead cost, policy restrictiveness, and potential for quality control (Kongstvedt, 2013).

Given the growing recognition of systems-level and ecological factors as being important for implementing and sustaining evidence-based practice (Raghavan et al., 2008), system-wide implementation research has been conducted to understand the naturalistic conditions and strategies through which evidence-based behavioral health practices are adopted, implemented, sustained, and scaled into routine care (Powell \& Beidas, 2016). This research supports the use of multifaceted initiatives that combine implementation strategies (e.g., training and consultation programs, organizational restructuring, financial incentives, policy changes) to target the complex barriers to system-wide implementation, such as lack of cultural responsiveness, limited funding, access to training, frequent workforce turnover, community engagement, low evaluation capacity, and low readiness to adopt innovations (Hoagwood et al., 2014; Fagan et al., 2019). However, it is not yet understood which strategies are most effective at eliciting sustained change across healthcare systems (Brookman-Frazee et al., 2016; Brookman-Frazee et al., 2018). Given the emphasis of cost reduction and quality improvement in MCOs, it is important for 
researchers to delineate the means by which certain strategies achieve sustainability and ensure that resources are being used as efficiently as possible.

\section{Learning Collaboratives}

A learning collaborative (LC), or quality improvement collaborative, is an implementation strategy in which clinical innovations are facilitated across networks of healthcare providers through shared educational experiences and problem-solving. Powell and colleagues (2015) defined LCs as "facilitat[ing] the formation of groups of providers or provider organizations and foster[ing] a collaborative learning environment to improve implementation of the clinical innovation" (Powell et al., 2015, p.8). LCs are often deployed by MCOs to implement evidence-based practices across provider networks (Hacker et al., 2014; Lloyd et al., 2015; MacDonald-Wilson et al., 2017). LCs have been applied to a wide range of clinical settings, such as primary care (Beers et al., 2017), community mental health (Cavaleri et al., 2010; Haine-Schlagel et al., 2013; MacDonald-Wilson et al., 2017), and child welfare agencies (Bartlett et al., 2016). Although their specific learning aims and design features (e.g., duration, size, participant roles) may vary, each LC shares the underlying goal of enabling organizations to make specific, measurable, and sustained improvements in clinical services (Nadeem et al., 2013; Nadeem et al., 2016).

LC initiatives in healthcare systems are often designed using the Institute of Healthcare Improvement's Breakthrough Series Collaborative Model as a guiding framework (Kilo, 1998; Schouten et al., 2008; Stephan et al., 2013; Nadeem et al., 2016). This model emphasizes collaborative participation between providers, involves participants from multiple professional roles (e.g., administrators, clinicians, managers, supervisors), and addresses behavior change at multiple levels within participating sites (i.e., organization-wide changes, clinician behaviors, 
patient outcomes). The Breakthrough Series model initiates change by selecting a clinical topic that the LC will be focused on achieving, organizing the group of LC personnel, identifying specific clinical behaviors that will be measured and targeted by participating providers, and completing a preparation or pre-work phase. During the LC, providers cycle between learning sessions where new knowledge or skills are acquired and action periods where the learned information is applied by the organization and targeted change behaviors are measured. At the end of each action period, progress on change behaviors and learning goals are assessed and this data is then used to inform future learning experiences. This cycle is referred to as a Plan-DoStudy-Act (PDSA) cycle. In addition to the PDSA cycles, information about lessons learned is shared between providers and with professionals in communities outside the LC. As goals are attained, additional providers may be recruited into the LC, or additional goals may be added (Kilo, 1999). A visualization of the Breakthrough Series Collaborative Model is provided in Appendix A.

Effectiveness Evidence. Although LCs can involve multiple costs (e.g., trainings, materials and toolkits, funding staff time; Dopp et al., 2017), they are often expected to improve service outcomes because they enact changes at multiple levels of the service setting and foster supportive, interorganizational relationships (Hanson et al., 2019; Nadeem et al., 2016; Nembhard, 2009). However, there is equivocal evidence demonstrating that LCs are effective. Although multiple studies have demonstrated positive effects of LCs on both service outcomes (i.e., session attendance and retention; Cavaleri et al., 2006; Cavaleri et al., 2010; Rutkowski et al., 2010) and quality service indicators (i.e., screening, training engagement, and diagnostic processes; Stephan et al., 2013; Nadeem et al., 2016), systematic reviews on LC effectiveness have been mixed. One systematic review conducted by Schouten and colleagues (2008) 
demonstrated limited, positive evidence of effectiveness of LCs on increasing providers' use of symptomology measures, patient satisfaction, and medical record indicators. Another review of LCs in medical service systems indicated that LCs were likely to have a robust, positive effects on changing provider behaviors but had weak effects on improving patient outcomes (Nadeem et al., 2013). Nadeem and colleagues (2014) reported that among 16 studies of LCs that were launched in mental health settings, only one study included a comparison condition, indicating a lack of rigor in this body of research.

One reason that research on LCs may show variable effects is the heterogeneity of LC designs and clinical contexts that are reported in the literature. A systematic review of $28 \mathrm{LCs}$ in mental health indicated that there are at least 14 unique LC components (e.g., trainings, in-person learning sessions, phone meetings, data collection, PDSA cycles) that have been reported, with each published LC averaging 7 specified components (Nadeem et al., 2014). Previous studies have not reported on LC design and structure with consistent levels of detail (Nadeem et al., 2013), and few studies have investigated which LC components are most important for implementation (Nembhard, 2009). In order to understand which components of LCs affect implementation, it is important for healthcare systems to report data on effectiveness and specify the LC components that were applied (Schouten et al., 2008; Nadeem et al., 2014).

Sustainability Evidence. Several previous studies have investigated the sustainment of clinical changes following the completion of LCs. There is evidence to suggest that LCs are capable of achieving sustainable shifts in community mental health care up to two years after active learning activities have ended (Cavaleri et al., 2007; Helseth et al., 2020; LoSavio et al., 2019). However, most of the research on LC sustainability has been descriptive (Cavaleri et al., 2007; Helseth et al., 2020; LoSavio et al., 2019; Nease et al., 2010; Noroña \& Acker, 2016), and 
only a few studies have examined theory-driven predictors of LC sustainability. Studies that have applied theory to this question have indicated that quality improvement components of the LC such as ongoing use of PDSA cycles, tracking outcomes data over time, and skill-building are positive predictors of sustainability (Ford et al., 2011; Hearld et al., 2016). Additional research is needed at this time to examine predictors of LC sustainability that are rooted in contemporary theory (Hearld et al., 2016).

\section{Learning Collaboratives and Trauma-Informed Care}

One way researchers have examined the effects and sustainability of LCs is through investigations of trauma-informed care implementation. Many implementation efforts focused on trauma-informed care and trauma-specific interventions feature LCs (Bartlett et al., 2016; Bunger et al., 2018; Lang et al., 2015; Dopp et al., 2017; Helseth et al., 2020; Noroña \& Acker, 2016), and the National Child Traumatic Stress Network has explicitly recommended LCs for increasing trauma-informed practices (Markiewicz et al., 2006). Globally, individuals will likely experience multiple traumatic events in their lifetime, which is concerning given that increased exposure to trauma and adversity is associated with poorer mental and physical health outcomes (Centers for Disease Control and Prevention, 2020). Improving health services for trauma survivors is currently perceived as a critical public health need, as evidenced by increased advocacy for trauma-informed clinical practices in policy and research funding (Substance Abuse and Mental Health Services Administration, n.d.; Beyerlein \& Bloch, 2014; Bowen \& Murshid, 2016; Levy-Carrick et al., 2019).

"Trauma-informed care" refers to the extent to which extant research on traumatization has informed the design of health service systems. A designation of trauma-informed signals that providers understand how trauma affects clinical outcomes and that these providers can 
effectively adapt their clinical interventions to meet the needs of trauma survivors (Harris \& Fallot, 2001; Butler, Critelli, \& Rinfrette, 2011; Reeves, 2015). Trauma-informed healthcare organizations should identify symptoms of trauma through screening, apply relevant traumarelated diagnoses, make referrals for trauma-specific treatment, minimize re-traumatization in daily workplace procedures, and establish a workplace culture that enables all staff (clinical or non-clinical) to behave in trauma-sensitive ways (Beldin \& Rolf, 2013; Reeves, 2015). Published investigations of trauma-informed care LCs (e.g., case studies, pre- and posttests) provide helpful insight into specific LC components that are important for implementing trauma-informed care, such as advise-seeking amongst clinicians (Bunger et al., 2018), reflective and relationship-based consultation practices (Noroña \& Acker, 2016), perceived organizational support for traumainformed practices (Helseth et al., 2020), organizational capacity, and readiness for change (Lang et al. 2016). Collectively, these studies highlight determinants of clinical change in LCs; however, theory-driven predictors of change are needed so that mechanisms of change can be eventually tested.

\section{A Theoretical Model for Studying Learning Collaboratives}

Very little is currently understood about the mechanisms by which LCs affect change in clinical innovation adoption and sustainability (McLeod et al., 2018); and more in-depth research on the means by which LCs affect organization-, clinician- and patient-level outcomes is needed in order to properly tailor LCs and maximize their benefits (Powell et al., 2019). Emerging literature in this area distinguishes implementation mechanisms, which describe how implementation occurs, from determinants of implementation, or the necessary conditions and factors that predict when implementation initiatives will be successful (Lewis et al., 2018). In order to investigate implementation mechanisms as they apply to LCs, theories must be applied 
that explain how LCs are expected to influence provider behaviors (Lewis et al., 2018; Michie et al., 2018). The Longitudinal Education for Advancing Practice (LEAP) model proposes various implementation mechanisms by which clinical training and consultation strategies are likely to impact the adoption and sustainability of new clinical innovations. The LEAP model draws on theories from other subfields of psychology, such as industrial-organizational, adult learning, and school-based learning (McLeod et al., 2018). To our knowledge, this model has not yet been applied to predict LC outcomes and sustainability.

The LEAP model is particularly appropriate for conceptualizing the means by which LCs affect clinician- and patient-level behavioral change because it is specific to training and consultation strategies. According to LEAP, training and consultation strategies such as LCs are expected to facilitate new clinical behaviors through changes in 3 dimensions: (1) cognitive changes (i.e., declarative knowledge, knowledge organization, cognitive strategies); (2) skill changes (i.e., initial acquisition, compilation, automaticity); and (3) attitude and relationship changes (i.e., attitudes towards the intervention, self-efficacy, trainee-trainer and traineeconsultant alliance). Further, the LEAP model conceptualizes learning as iterative process that unfolds across time, distinguishing initial training, long-term learning, and pre-training factors such as previous trainee experience, initial trainee attitudes and motivation, and the organizational environment (McLeod et al., 2018). To our knowledge, the LEAP model has not yet been applied to research on LCs; however, this model could progress our understanding of how participation in LC shifts clinical behaviors through shifts in clinician attitudes and skills.

\section{Current Study}

The current study investigated an LC deployed to implement trauma-informed care across a network of behavioral health providers affiliated with Community Care Behavioral 
Health Organization (Community Care). Community Care is a nonprofit behavioral health MCO that is a wholly owned subsidiary of the University of Pittsburgh Medical Center Insurance Services Division and acts in response to Pennsylvania's Medicaid behavioral health managed care program, HealthChoices. Community Care is a licensed, risk-assuming Health Maintenance Organization that operates through 11 service centers in various regions of Pennsylvania and manages care with public agencies in 41 counties through 11 separate contracts.

Funding and Origin. In 2015, an initiative to implement trauma-informed behavioral health services across the state of Pennsylvania was led by a partnership between the Behavioral Health Alliance of Rural Pennsylvania (BHARP), Community Care, and the Pennsylvania Office of Mental Health and Substance Abuse Services. The initiative was funded through a SAMHSA Systems of Care Grant that was awarded to BHARP and targeted mental health and substance abuse outpatient providers in 23 rural counties in the north central region of Pennsylvania. One of the core activities of the grant was to develop a trauma-informed system of care (i.e. the Trauma-Informed Care Project).

The Trauma-Informed Care Project was driven by an increased need for both mental health and substance abuse clinicians within Community Care's network who have competencies in managing trauma symptoms in individuals receiving outpatient services. Several practical barriers to delivering trauma-informed care were identified at Community Care before this initiative began, including: rural areas of service, few Master's-level clinicians, few opportunities and limited funding for training in trauma-informed care, inadequate supervision (e.g., supervision that did not incorporate best practices for trauma-informed care), and high rates of clinician turnover. These barriers necessitated an implementation approach that would promote 
system-wide behavioral changes. Thus, the BHARP Trauma Institute Learning Collaborative (TLC) was established.

TLC Aims. The goals of the BHARP Trauma-Informed Care Project were to establish trauma-informed organizational cultures at participating agencies, provide organization-level supports for implementing trauma-informed care in outpatient services, and provide trainings to clinicians at participating agencies in specific, evidence-based practices appropriate for treating clients who have experienced trauma. Specific aims for the TLC which were monitored through monthly data collection were to (1) increase staff confidence in delivery of trauma-informed care, (2) increase screening of individuals in service for exposure to trauma, and (3) increase the number of staff trained in trauma-informed care. Goals of the TLC were established as $90 \%$ of staff with high ratings of confidence (9/10 or 10/10) and $100 \%$ of individuals in service with screening for exposure to trauma.

TLC Personnel. Individuals who participated in the TLC comprised quality improvement teams that included various staff roles within each provider agency. Each provider was allowed to select personnel for their own quality improvement team; however, participation from multiple staff roles was encouraged. Each provider was required to include at least one individual from executive or leadership staff. Participation from clinical staff (e.g., clinicians, case managers, nurses), clinical supervisors, and individuals in service or their family members was also encouraged. Other roles that participated in quality improvement teams were Information Technology staff, quality management staff, peer support staff, and alumni from Community Care substance use programs.

TLC Design. The three aims of BHARP's Trauma-Informed Care Project were addressed by the TLC through a series of planned action steps. Aim 1 (i.e., establishing a trauma- 
informed organizational culture) was addressed by introducing agency-level TLC milestones, such as preparation, internal staff training, and developing workflows. Aim 2 (i.e., providing organizational supports for the use of TIC) was addressed by establishing Quality Improvement Teams; auditing data generated by each PDSA cycle and providing feedback on progress (e.g., milestone completion, training rates, screening rates, staff confidence); hosting monthly regional calls and webinars to discuss progress, barriers, and facilitators; hosting learning sessions with experts in trauma-informed care; and hosting quarterly in-person meetings to develop relationships and discuss lessons learned. Aim 3 (i.e., providing training to clinicians in traumaspecific services) was addressed by providing workshop trainings and consultation in evidencebased, trauma-specific interventions through a series of "BHARP Trauma Institutes."

The TLC occurred from September 2016 until December 2017. Time was divided into five 3-month quarters to provide a pause between multiple action periods and for measurement purposes. BHARP and the Systems of Care grant provided direct support for implementation efforts, and BHARP staff facilitated the TLC meetings. Community Care provided data management, and Community Care psychologists and psychiatrists provided consultation to quality improvement teams following clinical trainings.

Interventions and Practices. TLC providers received opportunities to be trained in multiple evidence-based, trauma-specific interventions. These interventions included: Seeking Safety (Najavits, 2002), Trauma-Focused Cognitive Behavioral Therapy (Cohen et al., 2016), Cognitive Processing Therapy (Resick et al., 2016), and Dialectical Behavior Therapy (Linehan, 2018). Additional practices that were also targeted by the TLC included: routine trauma symptom screening, inclusion of trauma-relevant diagnoses and treatment goals in progress notes, and a trauma-informed care training curriculum for all new and existing staff. 
Trauma-Informed Care Centers. Since the initial TLC was completed in December 2017, providers at Community Care have received the opportunity to engage in additional learning opportunities and become accredited as a Trauma-Informed Care Center (TICC). To become recognized as a TICC, providers are required to implement routine trauma screening and outcomes monitoring, provide annual trauma-informed care training to all new and existing clinical and non-clinical staff, supply trauma-informed supervision for clinical staff, provide trauma-informed debriefing training to supervisors and administrators, assess consumer satisfaction surveys, engage in monthly quality improvement team meetings, and implement evidence-based psychotherapies for trauma.

\section{Research Questions \& Hypotheses}

It is not currently understood how the TLC has impacted the sustainment of traumainformed practices across participating providers, and there is limited available knowledge regarding predictors of sustainable $\mathrm{LC}$ effects in the extant literature. Furthermore, variables that align with explanatory theoretical mechanisms of training have not been assessed in the TLC. Addressing these gaps is not only important for informing future designs of LC initiatives locally (i.e., within Community Care), but also for advancing the field's broader understanding of what predicts long-term LC impact. The following research questions were established to assess the impact of the TLC on short- and long-term changes in trauma-informed care quality indicators and evaluate the extent to which variables corresponding with the LEAP model (i.e., skill changes and attitude changes) were associated with sustained utilization of trauma-informed practices across providers. Time points for the proposed study were specified as the beginning of the TLC $\left(\mathrm{T}_{1}\right)$, the end of the TLC, which occurred 15 months later $\left(\mathrm{T}_{15}\right)$, and approximately three years after the TLC concluded, i.e. November $2020\left(T_{51}\right)$ or April $2021\left(T_{56}\right)$. Data from $T_{1}$ to 
$\mathrm{T}_{15}$ was collected on a monthly basis; and there was a 36 month gap with no active data collection between $\mathrm{T}_{15}$ and $\mathrm{T}_{51}$.

\section{Question 1}

To what extent did providers demonstrate improvement in trauma-informed care quality indicators (i.e., trauma symptom screening, use of trauma and stressor-related diagnoses, participation in staff trainings for trauma-informed care, clinician confidence in delivering trauma-informed care) from $\mathrm{T}_{1}$ to $\mathrm{T}_{15}$; and to what extent were improvements in traumainformed care outcomes sustained (i.e., maintained or improved across time) from $T_{15}$ to $T_{56}$ ?

Hypotheses: Trauma symptom screening rates, staff trauma-informed care training rates, utilization of trauma and stressor-related diagnoses, and staff confidence with using traumainformed care will increase from $T_{1}$ to $T_{15}$ and will be sustained (i.e., stay the same or continue to increase) from $\mathrm{T}_{15}$ to $\mathrm{T}_{56}$. These hypotheses are supported by literature demonstrating that $\mathrm{LC}$ participation improves quality service indicators like symptom screening and appropriate diagnostic coding (Stephan et al., 2013), and increases positive attitudes towards clinical innovations two years after implementation (Helseth et al., 2020).

\section{Question 2}

To what extent did providers demonstrate changes in service delivery outcomes (i.e., length of retention in care for individuals with a trauma diagnosis and density of outpatient services units received by individuals with a trauma diagnosis) from $\mathrm{T}_{1}$ to $\mathrm{T}_{15}$; and to what extent were improvements in service outcomes sustained (i.e., maintained or improved across time) from $\mathrm{T}_{15}$ to $\mathrm{T}_{51}$ ?

Hypotheses: Trauma service retention and trauma service density will increase from $\mathrm{T}_{1}$ to $T_{15}$ and will be sustained (i.e., stay the same or continue to increase) from $T_{15}$ to $T_{51}$. These 
hypotheses are supported by literature demonstrating that LCs increase service retention and attendance (Cavaleri et al., 2006; Cavaleri et al., 2010; Rutkowski et al., 2010).

\section{Question 3}

To what extent are attitude- and skill-based training variables (i.e., staff confidence delivering trauma-informed care, TLC milestone completion, TLC progress ratings, PDSA cycle quality between webinars) associated with TICC status among providers one and two years after the conclusion of the TLC?

Hypotheses: Providers' TICC status in 2018 (one year post-TLC) and 2019 (two years post-TLC) will be associated with increased TLC milestone completion, higher progress ratings during action periods, greater proportions of staff with high levels of confidence using traumainformed care, and higher objective PDSA quality ratings during the TLC. These hypotheses are supported the LEAP Model, which posits that clinical trainings are more likely to succeed when increasing provider skills and fostering positive attitudes towards clinical innovations (McLeod et al., 2018). These hypotheses are also supported by previous research that demonstrates improved attitudes towards evidence-based practices are associated with LC participation (Haine-Schlagel et al., 2013), as well as research demonstrating that engagement in LC trainings are associated with improved clinical behaviors (Nadeem et al., 2016).

\section{Methods}

\section{Participants}

The current study examined mental health and substance use provider agencies that participated in the TLC $(N=22)$ across 23 counties of the North Central region of Community Care. These provider agencies were representative of 29 unique clinic sites that deliver 
behavioral health services to both adults and children. Thirteen providers ( 13 sites) were mental health agencies, and 11 providers (16 sites) were substance use agencies.

TLC provider recruitment was coordinated by BHARP in a series of steps during the 6month prework stage of the TLC. First, county-level administrators at BHARP contacted sites in their own counties who were contracted with Community Care to gauge the interest level and ability to participate in the TLC. One mental health site and one substance abuse site per county or county joinder (i.e., counties that share administration or oversight) were selected. Next, BHARP contacted the sites that had been identified by administrative staff, provided further information about the Trauma-Informed Care Project (e.g., trainings that would be available, goals of the project, importance of trauma-informed care, commitment required, and staff who should participate), and offered a contract for sites to sign. Sites who signed a contract were included in the TLC and invited to a site kickoff event in April of 2016 that included an overview of the initiative and orientation to the training schedule. Following the site kickoff event, quality improvement teams were formed and personnel from each site were recruited into the TLC by agency leadership. An introductory session of TLC was conducted in August 2016. This initial meeting provided details to participating agencies about the LC model, specific objectives of the TLC, what data would be collected each month, an overview of the data collection methods, and an overview of quality improvement methods with practice of Plan, Do, Study, Act cycles. Apart from access to training opportunities, TLC personnel received no additional reimbursement for participation.

\section{Procedures}

This research was approved by the West Virginia University Institutional Review Board, (IRB Protocol \#2012193243). The project was confirmed by the review board as "not human 
subjects research" because it entailed a post hoc review of quality improvement and insurance records that were not identifiable by the investigator; thus, informed consent from providers to use data for the current study was not required. The current study utilized a longitudinal design, assessing providers at the beginning of the TLC $\left(\mathrm{T}_{1}\right)$, after the TLC $\left(\mathrm{T}_{15}\right)$, and three years after the end of the TLC $\left(\mathrm{T}_{51}\right)$. Data included archival records (i.e., insurance claims data, TLC tracking workbooks) that were collected as part of routine recordkeeping procedures at Community Care, as well as cross-sectional survey data that was collected for internal review of trauma-informed care sustainability at $\mathrm{T}_{56}$.

TLC Data Collection. Data collection during the TLC occurred during monthly webinar calls from September 2016 to December 2017. Data were collected, summarized, disseminated to TLC personnel, and stored by Community Care staff. Two weeks prior to each monthly webinars, sites were instructed to send in their progress data in the form of TLC Workbooks to Community Care staff for review. On each webinar call, providers discussed their data and quality improvement activities. Community Care summarized these data and presented them at the monthly webinars quarterly so that participating sites could see their progress in the TLC compared to the TLC as a whole. Data for mental health and substance use sites were presented separately and in aggregate. Participating sites received a report of their quarterly progress.

Post-TLC Data Collection. Trauma symptom screening rates, staff trauma-informed care training participation, and aggregated staff confidence in delivering trauma-informed care three years after the conclusion of the TLC were collected via a follow-up survey that was drafted by Community Care for internal quality review and shared with TLC faculty and BHARP for two rounds of review and edits. After finalizing survey content, this survey was administered via online platform by Community Care's outcome team (www.surveymonkey.com), and 30- 
minute phone interviews containing the same questions were also scheduled with each provider beginning immediately after the online survey was disseminated. All providers that had participated in the TLC were approached by Community Care staff during a virtually-hosted quarterly review meeting with TLC faculty. The leadership (e.g., clinical director) of each provider was then contacted individually by email, provided a link to the online survey form and a blank copy of the survey questions, and asked to schedule a time with Community Care staff (i.e., the investigator) for a phone interview. Providers who did not complete the entire online survey or respond to the phone survey invitation were sent up to two reminder emails. Each reminder email was timed to be sent approximately one week following the previous email request.

\section{Measures and Sources of Data}

Insurance Claims Data. Claims data records from Community Care were accessed to generate de-identified datasets on service outcome variables at each participating provider agency, including: (1) frequency of trauma and stressor-related diagnoses (e.g., Posttraumatic Stress Disorder, Acute Stress Disorder, Reactive Attachment Disorder), (2) length of retention in services for individuals diagnosed with trauma and stressor-related disorders, and (3) service density or number of units of service received for individuals diagnosed with trauma and stressor-related disorders.

TLC Workbook. The TLC workbook was used by each provider during the active TLC period (September 2016 to December 2017) to keep a monthly record of progress towards key TLC aims and processes. Only one workbook was kept by each provider agency, even those with multiple participating sites, and workbooks were submitted to the TLC faculty each month of the TLC for review. This workbook recorded agencies' self-reported trauma screening rates, self- 
reported number of staff trained in trauma-informed care, and self-reported ratings of staff confidence with using trauma-informed care on a 10-point, Likert-type scale $(0=$ not confidence, $10=$ extremely confident). The TLC workbook also recorded providers' monthly implementation progress ratings (i.e., they extent to which providers felt like they had implemented, tested, and sustained any personal trauma-informed care implementation goals) and the cumulative number of TLC milestones (which were the same for every provider) that had been addressed by the quality improvement team up to that month.

TLC milestone completion was calculated by indicating which action steps or discussion questions had been completed on a shared, composite checklist that was divided into 12 categories (e.g., laying the foundation, internal staff training, developing workflows, preparing for sustainability) based on stages of implementation. A total of 78 possible action steps or discussion questions were included in the milestone checklist for quality improvement teams to address during the TLC. Progress ratings were collected by asking providers to assign themselves a rating on a 10-point, Likert-type scale that increased by increments of $0.5(1=$ team established/no work accomplished, 5 = outstanding sustainable results). Both progress ratings and TLC milestone completion reflected the extent to which trauma-informed care principles had been implemented over time. A blank version of the TLC workbook is provided in Appendix B.

PDSA Quality Rating. Two independent raters who were employees of Community Care (not TLC faculty or any of the TLC providers) reviewed the final completed TLC workbooks from each provider at the end of the TLC period (i.e., after $\mathrm{T}_{15}$ ) to assign each provider one overall PDSA quality grade. Grades for PDSA quality could range from A+ to C-, and these were determined by the extent to which providers continuously set PDSA goals, gathered data that was relevant to assessing their goals, reviewed the relevant data, and recorded the results of 
their process in the TLC workbook. For the purposes of the current analyses, PDSA grades were converted to numerical quality ratings, such that a grade of $A+$ became a score of nine out of nine, and a grade of $\mathrm{C}$ - became a score of one out of nine, etc. Thus, higher PDSA quality ratings indicated greater proficiency in a providers engagement and utilization of PDSA cycles during the TLC (e.g., goal setting, data collection, goal review, and goal adjustment).

Trauma Informed Care Center (TICC) Organizational Application. At the end of the TLC, agencies were given the opportunity to sustain practices through a designation of "Trauma Informed Care Center" (TICC). The TICC designation process required providers to complete an electronic application form, supply supporting documentation to demonstrate that items on the application were completed and submit a TICC Organizational Self-Assessment Survey. On the TICC application form, providers were asked to report the extent to which they currently screen individuals in service for trauma symptoms, use outcomes monitoring in treatment, train their staff in trauma-informed care, apply trauma-informed supervision and debriefing practices, and measure consumer satisfaction. The TICC Organizational Self-Assessment Survey was to be completed by three staff members (one clinical, one executive, and one non-clinical) and collected by provider administrators during the TICC application process. Providers were provided with a TICC manual and scoring rubric at the time of requesting their application.

Faculty from the TLC, including clinical and administrative staff from Community Care, leadership from BHARP and TLC facilitators from BHARP, reviewed the application materials using an electronic scoring file and rubric. Both the total assessment score and rubric were used by reviewers to designate each provider as "not met" (i.e., temporary practices, lack of training), "acceptable" (i.e., TIC components fully integrated into care, TIC spread throughout the organization), or “exemplary” (i.e., integrated TIC practices and sustainability plan, TIC 
principles utilized in treatment planning and outcomes monitoring). Blank versions of the TICC Organizational Self-Assessment Survey and TICC scoring rubric are provided in Appendix B.

Provider Follow-Up Survey. A follow-up survey for providers at T56 (April 2021) was developed based on the wording of TLC aims questions in the original TLC workbook in order to assess the extent to which TLC providers are currently engaging in routine trauma-informed practices (i.e., staff trainings in trauma-informed care, trauma symptom screening rates, and staff confidence in using trauma-informed care). The design of this survey was stakeholder-informed, and questions were drafted and edited by TLC faculty and BHARP before it was administrated to provider agencies. This follow-up survey combined quantitative estimates of performance outcomes from the TLC workbooks with open-ended items to determine providers' perspectives of how sustainment had unfolded from 2017 to 2020. In addition, this survey collected demographic characteristics that were not accessible through existing TLC tracking materials, such as proportion of staff roles (clinical vs non-clinical), full-time equivalents for current employees, education level of staff, and any workforce turnover concerns in the past year.

\section{Data Analysis}

Changes across time in each of the trauma-informed care outcomes (i.e., trauma symptom screening, training rates, confidence delivering trauma-informed care, trauma diagnosis rates) and service outcomes (i.e., trauma-related service density, trauma-related service retention) were assessed during the active implementation/TLC period $\left(\mathrm{T}_{1}\right.$ to $\left.\mathrm{T}_{15}\right)$ using repeated measures analyses of variance (ANOVA). Changes in these same outcomes during the sustainment period ( $\mathrm{T}_{15}$ to $\left.\mathrm{T}_{56}\right)$ were assessed using paired-samples t-tests. Finally, associations between TICC status and LEAP model constructs (i.e., staff confidence delivering trauma-informed care, provider- 
reported implementation progress ratings, objective PDSA quality ratings, TLC milestone completion) were assessed using a linear mixed modeling approach.

Although logistic regressions were initially planned for the analysis of these LEAP model constructs as TICC status predictors, the sample size of these data was less than estimates for sample size at the time of the proposal (i.e., TICC status was found as being coded at the level of providers rather than at the level of individual sites). Thus, these data were not sufficiently powered to identify predictors of TICC status using logistic regression and an alternate approach was identified. Linear mixed modeling has the ability to assess data with a hierarchical structure, which was the case for the current repeated observations of outcomes that were nested within provider agencies. Mixed modeling approaches are also equipped to handle missingness in the data, which was appropriate given that not all TLC workbooks were completed every month by all participating providers.

\section{Results}

\section{Provider Characteristics}

A total of 22 providers participated in the TLC (12 mental health agencies and 10 substance use agencies). These providers consisted of 29 unique clinic sites that served 23 counties of the North Central region of Pennsylvania. Each provider formed a quality improvement team at $T_{1}$ that participated in TLC meetings, established monthly goals, and collected data for their agencies. The average quality improvement team size was 6.27 staff (SD $=2.19$; range $=2-11)$. Across these provider agencies, the average breakdown of staff education was $8.37 \%$ high school or GED-level ( $\mathrm{SD}=9.79 \%), 39.33 \%$ Bachelors-level $(\mathrm{SD}=25.70 \%)$, 45.47\% Masters-level ( $\mathrm{SD}=22.64 \%)$, and 6.89\% Doctoral-level ( $\mathrm{SD}=9.11 \%)$. Approximately $73.52 \%$ of staff at these agencies served in a clinical role $(\mathrm{SD}=25.08 \%)$, and $26.48 \%$ of staff 
served in a non-clinical role $(\mathrm{SD}=25.08 \%)$. A summary of key demographic characteristics of individuals in service at these providers from $T_{1}$ to $T_{51}$ are reported in Table 1.

\section{Descriptive Statistics.}

A total of 18 providers completed their final TLC workbook at $\mathrm{T}_{15}$. Three providers submitted their final workbook at $\mathrm{T}_{14}$, and one provider submitted their final workbook at $\mathrm{T}_{13}$. Provider follow-up surveys (either online, phone-based, or both) were collected for 19 out of 21 providers (90\%) who were still involved in the trauma-informed care initiative as of April 2021 ( $\left.\mathrm{T}_{56}\right)$. Of the two providers who were not interviewed at $\mathrm{T}_{56}$, one never responded to survey requests, and one cited scheduling barriers but confirmed an interest in being surveyed at a later date. A total of 16 providers completed the online version of the follow-up survey, and a total of 15 providers completed a phone survey.

A full summary of trauma-informed outcome variable means (i.e., trauma symptom screening rates, staff confidence delivering trauma-informed care, trauma-informed care training rates, utilization of trauma-related diagnostic codes), service outcome variable means (i.e., service unit density, and length of retention in services), and provider-reported progress rating means across time points is provided in Table 2. The average percentage of possible milestones that were addressed during the TLC by quality improvement teams was $77.27 \%$ (SD $=12.97 \%$ ). The average numerical PDSA quality rating assigned was 5.23 out of $9.00(\mathrm{SD}=2.18)$. Breakdowns of score frequencies observed for TLC milestone completion and PDSA quality across providers are reported in Tables 3 and 4, respectively. Correlations among study variables are reported in Table 5.

TICC Status. At one year post-TLC (2018), 21 providers were still taking part in the trauma-informed care initiative (i.e., one provider had withdrawn due to limited capacity to 
provide relevant services). Five of these providers (24\%) met "exemplary" TICC criteria, nine providers (43\%) met "acceptable" TICC criteria, and seven providers (33\%) did not meet criteria for TICC status in 2018. At two years post-TLC (2019), one site had merged with an existing provider for a total of 20 remaining providers. All providers still involved in the initiative in 2019 had qualified for TICC status, with 14 providers (70\%) meeting "exemplary” criteria and six providers (30\%) meeting "acceptable" criteria.

A series of independent t-tests were run to determine whether the outcome variables for the current study differed as a function of a providers' status as either a mental health or substance abuse agency. These analyses suggested that there were not significant differences between mental health and substance use sites for trauma symptom screening rates, the number of staff trained in trauma-informed care, rates of staff endorsing high level of confidence in the delivery of trauma-informed care, length of retention in care for trauma-related services, the percentage of TLC milestones that were completed, PDSA quality ratings, or provider-reported TLC progress ratings (all $p \geq .05$ ). However, mental health agencies reported higher percentages of trauma-related diagnoses relative to other diagnoses $(M=13.55, S D=8.72), t(19)=3.07, p=$ .006 , and a greater density of units that were billed for trauma-related services $(M=14.25, S D=$ $8.80), t(19)=3.50, p=.002$ compared to substance abuse agencies' reported trauma diagnosis rate $(M=3.55, S D=4.99)$ and trauma service density rate $(M=3.02, S D=4.40)$.

Q1. Trauma-Informed Care Outcomes. To what extent did providers demonstrate improvement in trauma-informed care quality indicators (i.e., rate of trauma symptom screening, rate of trauma-related diagnoses, participation in staff trainings for trauma-informed care, rates of high clinician confidence in delivering trauma-informed care) from $\mathrm{T}_{1}$ to $\mathrm{T}_{15}$ ? To what extent 
were improvements in these trauma-informed care outcomes sustained (maintained or improved) from $T_{15}$ to $T_{51}$ ?

During TLC ( $\mathbf{T}_{1}$ to $\left.\mathbf{T}_{15}\right)$. Repeated measures ANOVA were used to estimate changes in trauma symptom screening rates, staff trauma training rates, staff confidence ratings, and the percentage of trauma diagnoses billed during from $\mathrm{T}_{1}$ to $\mathrm{T}_{15}$. The amount of missingness for these outcome variables were $9.18 \%, 9.18 \%, 11.21 \%$, and $0.00 \%$, respectively. Missing values were missing at random via Little’s MCAR Test, $X^{2}(2583)=40.09, p=1.000$. Expectation maximization was used to estimate missing data points. For each ANOVA run, Mauchly's test of sphericity was violated (all $p<.001$ ); thus, the Greenhouse-Geisser correction was applied. Assumptions of normality (skew, kurtosis) for dependent variables were met all time points, unless otherwise noted. Only significant pairwise comparisons between time points are reported below. A summary of ANOVA results across all tested outcome variables is reported in Table 6. Trauma symptom screening. Trauma screening rates were measured as the percentage of individuals in service that received a trauma symptom screener each month. Mean trauma symptom screening rates were statistically significantly different across time points, $F(4.20$, $88.28)=8.90, p<.001 ; \prod^{2}{ }_{p}=0.30$. Pairwise comparisons for the full model are reported in Table 7. These comparisons indicated that a significant increase in trauma symptom screening occurred from the baseline trauma symptom screening rate occurred in July of 2017 ( $\left.\mathrm{T}_{11}\right)$, and this increased rate of screening was sustained through the end of the TLC.

Staff training. Staff training rate was measured as both the number of new staff that were trained each month and the number of cumulative staff trained over time. Assumptions of normality were not met for either the number of new staff trained each month or the cumulative number of staff trained; thus, the Friedman test (non-parametric alternative to repeated measures 
ANOVA) was used to analyze changes in these variables across time. The number of new staff trained in trauma-informed care each month decreased significantly, $X^{2}(1)=8.05, p=.005$, from $\mathrm{T}_{1}($ Mean $=23.32, \mathrm{SD}=41.53)$ to $\mathrm{T}_{15}($ Mean $=6.44, \mathrm{SD}=8.71)$. The number of cumulative staff trained in trauma-informed care increased significantly, $X^{2}(1)=22.00, p<.001$, from $\mathrm{T}_{1}$ $($ Mean $=23.32, \mathrm{SD}=41.53)$ to $\mathrm{T}_{15}($ Mean $=135.19, \mathrm{SD}=148.96)$.

Staff confidence. Staff confidence was measured as the percentage of surveyed staff who rated high levels of confidence in their ability to deliver trauma-informed care (9 or 10 out of 10) each month. Mean rates of high staff confidence in delivering trauma-informed care were statistically significantly different over time, $F(4.74,99.43)=17.19, p<.001 ; \prod^{2} p=0.45$. Pairwise comparisons for the full model are reported in Table 8. These comparisons indicated that a significant increase from the baseline percentage of staff who endorsed high levels of confidence occurred in July of 2017 ( $\left.\mathrm{T}_{11}\right)$, and this increased rate of screening was sustained through the end of the TLC.

Trauma-related diagnoses. Two sites were merged under one provider claims code, reducing the total sample to $n=21$ for this analysis. Trauma diagnosis rate was calculated as the percentage of services each month that were billed under a primary, secondary, or tertiary trauma-related diagnostic code out of all services billed (see Appendix C for a full list of codes used). The percent of trauma diagnoses relative to other diagnostic codes did not significantly changed across time, $F(2.40,48.06)=0.98, p=.394 ; \eta^{2} p=0.05$.

Sustainment ( $\mathbf{T}_{15}$ to $\mathbf{T}_{\mathbf{5 6}}$ ). Paired samples t-tests were run to assess the sustainment of trauma-informed care outcomes three years after the conclusion of the TLC (i.e., April 2021; $\mathrm{T}_{56}$ ). Although not all of the trauma-informed care outcomes had not improved during the active TLC period, these analyses were run as planned for all outcomes to identify whether delayed 
changes in any of the values had occurred between $T_{15}$ and $T_{56}$. All dependent variables at $T_{56}$ were normally distributed, unless noted otherwise.

Trauma symptom screening. There was no statistically significant change in the percent of individuals who received a trauma symptom screener from $\mathrm{T}_{15}($ Mean $=92.03, \mathrm{SD}=10.85)$ to $\mathrm{T}_{56}($ Mean $=86.05, \mathrm{SD}=25.13), t(21)=0.92, p=.368 ; d=0.20$.

Staff training. The cumulative number of staff trained at $\mathrm{T}_{56}$ was not normally distributed; thus, the Wilcoxon signed-rank test (non-parametric alternative to paired samples t-test) was used. This test indicated significant increase in the number of staff trained by providers from $T_{15}$ to $($ Mean $=135.19, \mathrm{SD}=148.96) \mathrm{T}_{56},($ Mean $=166.25, \mathrm{SD}=149.42), Z=-3.04, p=.002$.

Staff confidence. There was a significant decrease in the percent of individuals who endorsed high levels of confidence with trauma-informed care from $\mathrm{T}_{15}$ (Mean $=76.38, \mathrm{SD}=$ 17.53) to $\mathrm{T}_{56}($ Mean $=34.46, \mathrm{SD}=26.61), t(21)=7.45, p<.001 ; d=1.59$.

Trauma-related diagnoses. There was no statistically significant change in the percent of services billed under a trauma diagnosis from $\mathrm{T}_{15}(\mathrm{Mean}=9.19, \mathrm{SD}=9.24)$ to $\mathrm{T}_{51}($ Mean $=9.44$, $\mathrm{SD}=10.52), t(18)=-0.22, p=.825 ; d=-0.05$.

Q2. Service Delivery Outcomes. To what extent did providers demonstrate changes in service delivery outcomes (i.e., length of retention in care for individuals with a trauma diagnosis; density of outpatient services units received by individuals with a trauma diagnosis) from $T_{1}$ to $\mathrm{T}_{15}$, and to what extent were improvements in service outcomes sustained (i.e., maintained or improved across time) from $T_{15}$ to $T_{51}$ ?

During TLC ( $\mathbf{T}_{\mathbf{1}}$ to $\left.\mathbf{T}_{\mathbf{1 5}}\right)$. Repeated measures ANOVA were used to estimate changes in density (i.e., proportion of units billed under trauma-related diagnoses out of all units billed) and service retention (i.e., proportion of days in service for individuals with a trauma-related 
diagnosis out of days in service for all individuals) during the TLC ( $\mathrm{T}_{1}$ to $\left.\mathrm{T}_{15}\right)$. Missing values in claims data were missing completely at random via Little's MCAR Test, $X^{2}(191)=33.51, p=$ 1.00. For each ANOVA, Mauchly's test of sphericity was violated (all $p<.001$ ); thus, the Greenhouse-Geisser correction was applied. Assumptions of normality were met at all time points. These ANOVAs revealed that mean trauma service density did not change significantly over time, $F(1.13,22.50)=1.15, p=.303 ; \prod^{2} p=0.05$. Likewise, mean retention for individuals diagnosed with trauma did not change significantly over time, $F(1.17,23.42)=1.08, p=.322$; $\eta^{2}{ }_{p}=0.05$.

Sustainment ( $\mathbf{T}_{15}$ to $\left.\mathbf{T}_{\mathbf{5 6}}\right)$. A paired samples t-tests was run to assess sustainment of density and retention values from the end of the TLC to the three-year follow-up ( $\mathrm{T}_{15}$ to $\left.\mathrm{T}_{51}\right)$. Assumptions of normality were met at both time points for both variables. These tests revealed that there was no significant change in trauma service density from $\mathrm{T}_{15}(\mathrm{Mean}=9.14, \mathrm{SD}=9.50)$ to $\mathrm{T}_{51}($ Mean $=8.81, \mathrm{SD}=10.56), t(18)=0.30, p=.765 ; d=0.07$. Further, there was no significant change in trauma service retention from $\mathrm{T}_{15}(\mathrm{Mean}=62.91, \mathrm{SD}=40.88)$ to $\mathrm{T}_{51}(\mathrm{Mean}$ $=56.81, \mathrm{SD}=66.26), t(16)=0.58, p=.574 ; d=0.14$.

Q3. TICC Status. To what extent are attitude- and skill-based training variables (i.e., staff confidence delivering trauma-informed care, TLC milestone completion, TLC progress ratings, PDSA cycle quality between webinars) associated with TICC status among providers one and two years after the conclusion of the TLC?

Linear mixed modeling was performed to assess whether changes in skill- and attituderelated variables over time varied as a function of TICC status in 2018 and in 2019. To establish whether the posited models improved fit to the data, a baseline model of change over time was run before TICC status was added as a predictor. 
Staff Confidence. Staff confidence was measured as the percentage of surveyed staff who rated high levels of confidence in their ability to deliver trauma-informed care (9 or 10 out of 10) each month. A baseline model was run to assess changes in the percentage of staff who had high confidence in their ability to use trauma-informed care across time. This model indicated that high confidence rates increased significantly from $\mathrm{T}_{1}$ to $\mathrm{T}_{15}, F(14,116.03)=$ $10.68, p<.001$. The full model for 2018 TICC status and time as predictors of high staff confidence did not significantly improve fit compared to the baseline model, $X^{2}(2)=1.03, p=$ .598. When accounting for changes over time, 2018 TICC status was not significantly associated with high staff confidence, $F(2,37.00)=0.81, p=.454$. Similarly, the full model for 2019 TICC status and time did not significantly improve fit compared to the baseline model, $X^{2}(2)=0.07, p$ $=.965$. When accounting for changes over time, 2019 TICC status was not significantly associated with high staff confidence, $F(2,37.99)=0.04, p=.962$.

TLC Milestones. TLC milestone completion was calculated as the cumulative number of TLC milestone categories or stages of implementation (out of 12) that were addressed by the quality improvement team each month. A baseline model was run to assess changes in the number of TLC milestones addressed by the quality improvement teams across time. This model indicated that the number of milestones addressed increased significantly from $\mathrm{T}_{1}$ to $\mathrm{T}_{15}, F(14$, $120.00)=41.39, p<.001$. The full model for 2018 TICC status and time as predictors of TLC milestone completion did significantly improve fit compared to the baseline model, $X^{2}(2)=7.72$, $p=.021$. When accounting for changes over time, 2018 TICC status was significantly associated with the number of milestones addressed, $F(2,43.34)=4.42, p=.018$. An examination of parameter estimates revealed that the number of milestone completed was significantly greater for providers who met "exemplary" status in 2018 compared to providers who met "acceptable" 
status $($ Estimate $=-1.37, p=.005)$, and providers who did not meet TICC standards, $($ Estimate $=$ $-0.98, p=.045)$. The full model for 2019 TICC status and time did not significantly improve fit compared to the baseline model, $X^{2}(2)=1.24, p=.538$. When accounting for changes over time, 2019 TICC status was not significantly associated with the number of milestones addressed, $F(2$, 42.86) $=0.81, p=.451$.

Progress Ratings. Provider progress ratings were calculated as the self-reported score that was generated by quality improvement teams regarding their own implementation of traumainformed care goals each month. A baseline model was run to assess changes in providerreported progress rating across time. This model indicated that progress ratings increased significantly from $\mathrm{T}_{1}$ to $\mathrm{T}_{15}, F(14,110.66)=52.99, p<.001$. The full model for $2018 \mathrm{TICC}$ status and time as predictors of progress rating did not significantly improve fit compared to the baseline model, $X^{2}(2)=1.46, p=.481$. When accounting for changes over time, 2018 TICC status was not significantly associated with progress ratings, $F(2,56.35)=0.95, p=.394$. The full model for 2019 TICC status and time did not significantly improve fit compared to the baseline model, $X^{2}(2)=4.75, p=.093$. When accounting for changes over time, 2019 TICC status was not significantly associated with progress ratings, $F(2,55.74)=2.82, p=.068$.

PDSA quality rating. PDSA quality ratings were calculated as an objective rating of how well providers engaged with and completed monthly PDSA cycles each month. Only one PDSA quality rating was assigned to each provider; thus, changes in PDSA quality over time were not relevant and the final model was compared to an intercept-only baseline model for PDSA quality. The full model for 2018 TICC status and PDSA quality did not significantly improve fit compared to the baseline model, $X^{2}(2)=1.43, p=.488$. This model indicated that 2018 TICC status was not significantly associated with progress ratings, $F(2,330)=0.72, p=$ 
.488. The full model for 2019 TICC status and PDSA quality did significantly improve fit compared to the baseline model, $X^{2}(2)=22.57, p<.001$. This model indicated that 2019 TICC status was significantly associated with PDSA quality ratings, $F(2,330)=11.68, p<.001$. An examination of parameter estimates revealed that the number of PDSA quality ratings were significantly higher for providers who met "exemplary" status in 2019 compared to providers who met "acceptable" status (Estimate $=-1.24, p<.001)$.

\section{Discussion}

The current study found that certain trauma-informed care outcomes (i.e., trauma symptom screening rates, provider confidence in delivering trauma-informed care, and number of staff trained in trauma-informed care) increased significantly during the TLC. Improved screening and confidence rates were sustained three years after the conclusion of the TLC, while perceptions of confidence had significantly decreased during this time. The rate of traumarelated diagnostic code use and service-related outcome variables (i.e., density of units received and duration of retention in care) did not change significantly over the TLC period or across the three-year sustainment phase. Finally, provider self-reported completion of implementation milestones during the TLC was associated with trauma-informed care behaviors one year after the TLC, while objective ratings of PDSA quality (i.e., engagement and appropriate utilization of feedback data) was associated with trauma-informed care behaviors two years after the TLC.

Interestingly, a significant increase in both staff confidence and screening rates were observed at the same timepoint 11 months after the TLC began, indicating that these changes could be related to one another. For instance, it is possible that improvements in an organizations' capacity to accurately identify trauma symptoms affected their perceived selfefficacy regarding trauma-informed care. It is also possible that both staff confidence and trauma 
screening behaviors were both influenced by a third factor that was not accounted for in these data. These gradual increases in screening behavior, training behavior, and confidence ratings are in support of our hypothesis that trauma-informed outcomes would improve over time. Such findings are consistent with previous literature on changes in trauma services following LC implementation initiatives (Bartlett et al., 2016; Bunger et al., 2018; Lang et al., 2015; Dopp et al., 2017; Helseth et al., 2020; Noroña \& Acker, 2016) and support the TLC as a useful strategy for improving organizational capacity to apply trauma-informed behavioral healthcare.

The proportion of trauma-related diagnoses relative to other diagnostic codes did not change significantly over time. Differences in other service outcomes over time (i.e., retention in service and density of units billed for individuals with a trauma diagnosis) were also nonsignificant. These results are initially surprising considering previous research that found professional collaboratives to be useful for improving appropriate diagnostic coding (Stephan et al., 2013), as well as our earlier finding that trauma screening and provider confidence with using trauma-informed care increased across time. However, there are many potential explanations for why a changes in rates of diagnostic coding for trauma did not occur. First, the expectation for increased diagnosing of trauma-related disorders assumes that these disorders were underdiagnosed prior to beginning the TLC. It cannot be confirmed from the current data whether trauma diagnosing at baseline was not an accurate reflection of the true trauma population at these agencies. The average rate of trauma diagnosis in our study ranged between 9-10\% across all providers. Taken with existing literature on lifetime prevalence of posttraumatic stress symptoms in the general population (7-12\%) and extensive extant research which shows that prevalence for trauma symptoms is higher among populations treated for substance use and serious mental illness (Grubaugh et al., 2011), our data may be consistent with what is expected 
for our population. If misdiagnosing were not an issue for these agencies at baseline, there would be no reason to expect these rates to change across time.

Alternately, it is possible that a lack of significant findings for trauma diagnosis-related outcomes can be tied to a systemic issue in how diagnostic codes are assigned by providers. If this were the case, the current data would only reflect a subsample of the individuals in service who actually received treatment for trauma symptoms. Because self-reported data from the TLC show increases in trauma-informed practices but claims data does not reflect a similar change, there may be a disconnect in the clinical workflow between clinicians and individuals who process insurance claims (i.e., the clinician providing a service is not the same individual who goes on to process the paperwork to bill for that service), or the codes that are used for billing vary as a function of what is likely to get reimbursed rather than as a function of the treatment goals. This may be particularly relevant for sites addressing substance use and serious mental illness, where trauma codes are not always necessary to receive payment for a claim. This possibility is supported by our finding in the descriptive analyses that substance abuse agencies reported smaller percentages of trauma-related diagnoses compared to mental health agencies. It should also be noted that an initial diagnosis might not be updated or changed in claims data once it's made (even if clinician conceptualization for treatment changes), and the specific types of codes that are reimbursable can change based on a clinicians' licensure status (Dormond \& Afayee, 2016).

Because we do not have direct access to the progress notes that were written by clinicians at these agencies, we cannot account for how the actual content of the therapy sessions changed across time. It is likely based on provider reports during the TLC and positive commentary about the sustainment of these practices during the follow-up interviews that trauma-specific 
interventions are being used to a larger extent than is reflected by the frequency of traumarelated diagnostic codes. Future studies should find a way of accessing information about what occurs in session (e.g., progress note or chart records). Although this can be burdensome for MCOs to collect progress note data for large samples of clinicians, management or supervisors may be able to aid with this reporting, and it may provide a more accurate view of how implementation efforts shape clinical conceptualization and treatment processes.

TICC status in 2018 (but not 2019) was associated with the number milestones addressed and TICC status in 2019 (but not 2018) was associated with PDSA quality ratings that were assigned by the TLC faculty/outcomes team. No other variables associated with the LEAP Model (i.e., staff confidence, progress ratings) were significantly associated with TICC status after the conclusion of the learning collaborative. These findings may speak to factors that are important for initial implementation and later-stage implementation or sustainability. Factors and strategies that are needed to initiate implementation (catalysts to change) may be different from the factors and strategies that are important for maintaining gains. The variable associated with 2018 outcomes was milestone completion, which represents the providers' ability to problem solve, incentivize, and demonstrate an organizational commitment to delivering trauma-informed care; whereas long-term (2019) TICC status was associated with PDSA quality ratings, which represent the providers' ability to engage in iterative feedback cycles (i.e., establish an actionable goal, collect data, review results, and adjust new goal). These variables represent unique but intersecting skillsets. Although both measures reflect maturation in the providers' ability to deliver trauma-informed services, PDSA quality, or the ability to engage appropriately in iterative feedback cycles, reflects a quality improvement competency that can transcend specific implementation initiatives. It is possible that trauma-specific skills are needed to initially 
implement trauma-informed care at the organizational level, while additional competencies in data collection, self-reflection, and goal-setting are needed to sustain trauma-informed care longer term.

A lack of association between staff-reported confidence in delivering trauma informed care or provider-reported progress ratings with TICC status in 2018 or 2019 may have both measurement and theoretical explanations. There was no required minimum number staff established for completing the confidence survey at each provider agency; and the denominator of individuals surveyed could vary from month to month (i.e., this number is not representative of the same subsample across all the time points). It is also possible that these constructs (i.e., staff confidence using trauma-informed care and provider-reported progress ratings), while they co-occur with implementation success, are not sufficient to promote changes in clinical practice. More complex modeling of these factors (e.g., combining skill, knowledge, social, and attitude variables), supported by a larger sample of providers, could provide useful insight into the combined influence of multiple constructs on sustainability. Such modeling would be more reflective of the LEAP model, which posits that attitudes work in conjunction with skills, knowledge building, and relationships to influence clinical change.

Analyses of outcome sustainability three years after the conclusion of the TLC revealed that the percent of individuals in service who received a trauma screener and the number of staff who received training in principles of trauma-informed care was sustained from November 2017 to April 2021. This supports the ability of TLC to maintain gains in behaviors that are important for trauma-informed practice over long intervals of time. This finding provides an important addition to the extant literature, which has previously only demonstrated one- or two-year maintenance of trauma-informed care behaviors following a LC implementation (Cavaleri et al., 
2007; Helseth et al., 2020; LoSavio et al., 2019). Indeed, these data suggest that LC approaches could have long-term effects that justify the intensive resources that are needed to design and implement LCs.

The proportion of services billed under a trauma-related diagnosis, the number of units billed for trauma-related services, and the days of retention in care for individuals with a traumarelated diagnosis remained the same from the conclusion of the TLC to the three-year follow-up period. In light of the finding that trauma-related diagnosis rates, trauma service density, and trauma service retention remained stable across the 15 -month TLC period, this finding is not surprising. The same factors maintaining these variables from September 2016 to November 2017 (that are not reflected in the current study) are also likely affecting these scores from November 2017 to November 2020.

A surprising finding in the sustainability analyses was that providers self-reported confidence in the delivery of trauma informed care decreased from November 2017 to April 2021. One previous study by Kopelovich and colleagues (2019) applied a LC approach to implement cognitive behavioral therapy for psychosis in a similarly large service system. The authors noted a significant drop in clinicians' self-perceived skill level from the training period to the initial consultation interval after training. As these authors suggest, it is possible that staff perceptions of self-efficacy naturally decrease as a function of having initial implementation supports removed and that self-efficacy needs to be slowly reestablished over time as more clinical experiences are gained (Kopelovich et al., 2019). It is possible that confidence in delivering these services was supported by active engagement in the TLC each month and the ability to network or share resources with other providers, which was then withdrawn after $\mathrm{T}_{15}$. 
During the follow-up surveys conducted with providers, approximately $53 \%$ of the providers surveyed indicated some concerns with staff turnover or an impact of clinician turnover on their ability to deliver trauma-informed services. Workforce turnover is a welldocumented barrier to implementation efforts in behavioral health settings, and it can result in negative impacts (e.g., burnout, stress, increase burden) on the remaining staff in these organizations (Brabson et al., 2020). Although an analysis of turnover is beyond the scope of the current research questions, this may provide a useful explanation for why confidence ratings decreased across the three-year period. Given that the providers in our study work in predominantly rural areas, staff rehiring may also be particularly difficult due to a lower population density. This could make it more challenging for providers to hire new clinicians who are experienced and licensed, and hiring staff with less experience could result in reduced staff confidence.

In light of the finding that changes in staff confidence and trauma symptom screening rates co-occurred during the TLC, it is interesting that screening rates were sustained through $\mathrm{T}_{56}$ while confidence decreased. This contradicts previous research which showed sustained improvements in provider attitudes towards trauma-specific treatments following a LC implementation (Helseth et al., 2020); however it is important to distinguish confidence in ones' ability to use a clinical innovation and general attitudes of approval towards that innovation. Confidence is likely affected by other factors beyond an agency's ability to routinely screen for and identify trauma symptoms. This would make sense due to the fact that confidence in our study was assessed generally (i.e., not specific to one behavior or aspect of trauma-informed care); thus, a reduction in confidence could be associated with self-efficacy as it pertains to several other clinical behaviors (e.g., supervision seeking, ongoing training attendance, etc.). 
Further, lower confidence during the sustainment phase does not necessarily indicate a decreased capacity on the part of providers to actually deliver trauma-informed care.

Given the longitudinal nature of this research, it is also important to document elements of the historical context in which our study took place. The spread of the SARS-CoV-2 virus in spring of 2020 began to influence the ways that providers deliver behavioral and substance use services for over a year of the three-year sustainment period. For instance, many providers transitioned rapidly to telehealth services or had to make changes in clinical workflows to accommodate the public health crisis (Haque 2021); however, these services continue to be underutilized by substance abuse populations (Lin et al., 2019). Mental health providers and individuals in service have reported increased rates of stress and burnout, which has the ability to influence organizational culture, staff turnover, and quality of care that is delivered to patients (Kelly \& Hearld, 2020). Thus, it is important to recognize that questions any questions related to the sustainability of trauma-informed care were influenced by SARS-CoV-2 and the broader strain it has put on health service systems in the United States. Future research will be critical to demonstrate whether factors that were associated with sustainability in our study are consistent in different sociomedical contexts.

Limitations. Claims data has several limitations including that its primary purpose is for billing, and not for research; however, it is sometimes used by MCOs to better understand patterns of service utilization (Tyree et al., 2006). Given this, there may be bias in how codes are billed in order to ensure payment for services. The ability of claims data to characterize the sample of individuals in service is also limited, as they do not account for gender identities, but only biological sex as recorded by the MCO. 
The TLC workbook includes several variables that are self-report and is therefore subject to reporter bias. Across workbooks, there was variability in the extent to which providers described their experiences with specific milestones (i.e., some sites would cite specific individuals who were present, agenda items for each month, etc.; while others would only indicate dichotomously whether the milestone was addressed, Yes/No). It should also be noted that the data for the TLC workbooks and the follow-up survey was collected through the MCO (Community Care), which serves in the role as payer for these providers. Despite efforts on the part of Community Care to foster collaborative and open communication with providers, this existing relationship and an implicit expectation that trauma services are maintained in TICCdesignated sites may have influenced provider responses by placing demand characteristics on providers to overestimate their success using trauma-informed care.

There were also some limitations to the methodology used for collecting provider followup surveys. Specifically, providers had limited times available to schedule interviews with the investigator, and these were often capped at 30-minute intervals for the convenience of the providers. Because the investigator was unable to record transcripts of the phone call per MCO policy, note taking took up some of the interview time and not all questions were administered as a result. The limited time window was addressed by prioritizing questions that were necessary to run the planned analyses and ensuring that all providers yielded necessary scores for trauma symptom screening, training rates, and confidence.

Regarding the study design, there was a gap in observations for TLC workbook variables between end of the TLC and 3-year follow-up. The current study is post-hoc and does not directly test skill- and attitude-related variables. Further, the providers that were selected for participation in our study were not randomized (i.e., there is a likelihood that sites that 
administrators believed would be best suited to implement trauma-informed care were initially selected by BHARP). To better understand the role that skills and attitude development play in the progression of implementation, future research should focus on designing true experiments that manipulate the cultivation of specific skill sets and randomize participants by condition.

Strengths. Despite these limitations, the current study also contained several important strengths. This is the first study to examine training- and skill-related variables in association with the sustainability of LC outcomes for trauma-informed care. As a result, these data have the potential to inform changes in training initiatives within Community Care and BHARP, as well as the broader body of literature on the use of LCs in system-wide implementation. The Breakthrough Series model, which informed the design of the TLC reported in the current study, has been used extensively for health system improvement initiatives (Cavaleri et al., 2010; Haine-Schlagel et al., 2013; MacDonald-Wilson et al., 2017), and it is therefore likely that these results will be applicable to other MCOs and provider organizations.

A large percentage of providers who initially took part in the TLC responded to the threeyear follow-up survey, so attrition was not an issue for these analyses, and results that were collected at $\mathrm{T}_{56}$ are likely representative of most of the providers who participated in active implementation. This study also combines objective and subjective reports of implementation progress (i.e., TICC status and PDSA ratings were determined by a third party review process). The current study also contained several repeated observations that were collected at the same time points for each provider, increasing robustness of statistical results during the TLC period. Finally, access to insurance claims data was an important strength of this study, as this enabled investigators to service utilization patterns from multiple perspectives or sources of information. 
Conclusion. Learning collaboratives may be a viable means of improving and sustaining trauma-informed care outcomes, such as trauma symptom screening rates, training of staff in trauma-informed care principles, and staff-reported confidence in applying trauma-informed care. To maximize the sustainability of these implementation efforts, LC faculty should (1) encourage providers to address several stages of implementation (i.e., milestones) while active supports from the TLC are in place and (2) foster and attend to provider engagement in PDSA processes. Our findings suggest that trauma-informed care sustainment may be maximized by attending to both trauma-specific and broader quality improvement competencies.

Future research should continue to experimentally examine skill development and provider attitudes as they relate to sustained implementation following a large-scale clinical training initiative. Combined modeling of constructs from the LEAP model with a larger sample of providers could provide important insight into how each of these factors differentially influence short- and long-term implementation processes. Further analysis of the qualitative survey data that was collected in the current study's provider follow-up surveys should also be conducted and incorporated with these results to better contextualize and understand the firsthand experiences of the TLC providers. Taken together, these data could provide important information about the unique barriers and facilitators to training provider agencies in the various competencies that are essential for providing a trauma-informed system of care. 


\section{References Cited}

Bartlett, J., Barto, B., Griffin, J., Fraser, J., Hodgdon, H., \& Bodian, R. (2016). Trauma-informed care in the Massachusetts child trauma project. Child Maltreatment, 21(2), 101-112. https://doi.org/10.1177/1077559515615700

Beers, L. S., Godoy, L., John, T., Long, M., Biel, M. G., Anthony, B., Mlynarski, L., Moon, R., \& Weissman, M. (2017). Mental health screening quality improvement learning collaborative in pediatric primary care. Pediatrics, $140(6)$. https://doi.org/10.1542/peds.2016-2966

Beldin, K. L., \& Rolf, K. A. (2013). Becoming trauma-informed: Suggestions for incorporating research findings into practice. Professional Development, 16(1). http://www.profdevjournal.org/articles/161030.pdf

Beyerlein, B. A., \& Bloch, E. (2014). Need for trauma-informed care within the foster care system: A policy issue. Child Welfare, 93(3), 7. https://wvu.idm.oclc.org/login?url=https://www.proquest.com/scholarly-journals/needtrauma-informed-care-within-foster-system/docview/1804471300/se-2?accountid=2837

Bowen, E. A., \& Murshid, N. S. (2016). Trauma-informed social policy: A conceptual framework for policy analysis and advocacy. American Journal of Public Health, 106(2), 223-229. https://doi.org/10.2105/AJPH.2015.302970

Brabson, L. A., Harris, J. L., Lindhiem, O., \& Herschell, A. D. (2020). Workforce turnover in community behavioral health agencies in the USA: A systematic review with recommendations. Clinical Child and Family Psychology Review, 23(3), 297-315. https://doi.org/10.1007/s10567-020-00313-5 
Brookman-Frazee, L., Stadnick, N., Roesch, S., Regan, J., Barnett, M., Bando, L., InnesGomberg, D., \& Lau, A. (2016). Measuring sustainment of multiple practices fiscally mandated in children's mental health services. Administration and Policy in Mental Health and Mental Health Services Research, 43(6), 1009-1022. https://doi.org/10.1007/s10488-016-0731-8

Brookman-Frazee, L., Zhan, C., Stadnick, N., Sommerfeld, D., Roesch, S., Aarons, G. A., InnesGomberg, D., Bando, L., \& Lau, A. S. (2018). Using survival analysis to understand patterns of sustainment within a system-driven implementation of multiple evidencebased practices for children's mental health services. Frontiers in Public Health, 6, 54. https://doi.org/10.3389/fpubh.2018.00054

Bunger, A. C., Doogan, N., Hanson, R. F., \& Birken, S. A. (2018). Advice-seeking during implementation: a network study of clinicians participating in a LC. Implementation Science, 13(1), 101. https://doi.org/10.1186/s13012-018-0797-7

Butler, L. D., Critelli, F. M., \& Rinfrette, E. S. (2011). Trauma-informed care and mental health. Directions in Psychiatry, 31(3), 197-212. https://www.researchgate.net/profile/Lisa-Butler-5/publication/234155324_TraumaInformed_Care_and_Mental_Health/links/02bfe50f9b4cbb8051000000/Trauma$\underline{\text { Informed-Care-and-Mental-Health.pdf }}$

Cavaleri, M., Gopalan, G., McKay, M., Appel, A., Bannon, W., Bigley, M., ... \& Sher, T. (2006). Impact of a learning collaborative to improve child mental health service use among lowincome urban youth and families. Best Practices in Mental Health, 2(2), 67-80. https://web.b.ebscohost.com/ehost/pdfviewer/pdfviewer?vid=0\&sid=db94ed39-5f3742fe-a50a-de725e8b22a5\%40sessionmgr102 
Cavaleri, M. A., Gopalan, G., McKay, M. M., Messam, T., Velez, E., \& Elwyn, L. (2010). The effect of a learning collaborative to improve engagement in child mental health services. Children and Youth Services Review, 32(2), 281-285. https://doi.org/10.1016/j.childyouth.2009.09.007

Cavaleri, M.A., Franco, L. M., McKay, M. M., Appel, A., Bannon, W., Bigley, M., Fazio, M., Gopalan, G., Harrison, M., Salerno, A., \& Thaler, S. (2007). The sustainability of a learning collaborative to improve mental health service use among low-income urban youth and families. Best Practices in Mental Health, 3(2), 52-61. https://web.b.ebscohost.com/ehost/pdfviewer/pdfviewer?vid=0\&sid=5a7189b3-e7a840e7-bc1f-cbd33cf7921d\%40sessionmgr103

Centers for Disease Control and Prevention (2020, April 03). Preventing Adverse Childhood Experiences. CDC. Retrieved September 13, 2020, from https://www.cdc.gov/violenceprevention/aces/fastfact.html

Cohen, J. A., Mannarino, A. P., \& Deblinger, E. (2016). Treating trauma and traumatic grief in children and adolescents. Guilford Publications.

Dopp, A. R., Hanson, R. F., Saunders, B. E., Dismuke, C. E., \& Moreland, A. D. (2017). Community-based implementation of trauma-focused interventions for youth: Economic impact of the learning collaborative model. Psychological Services, 14(1), 57-65. https://doi.org/10.1037/ser0000131

Dormond, M., \& Afayee, S. (2016). Understanding billing restrictions for behavioral health providers. Retrieved from http://www.casoluisfgonzalezcolon.com/images/FA3P4_Billing-Restrictions_FullReport.pdf April 1, 2021. 
Enthoven, A., Fuchs, V. R., \& Shortell, S. M. (2019). To Control Costs Expand Managed Care and Managed Competition. JAMA, 322(21), 2075-2076. https://doi.org/10.1001/jama.2019.17147

Fagan, A. A., Bumbarger, B. K., Barth, R. P., Bradshaw, C. P., Cooper, B. R., Supplee, L. H., \& Walker, D. K. (2019). Scaling up evidence-based interventions in US Public Systems to prevent behavioral health problems: Challenges and opportunities. Prevention Science, 20(8), 1147-1168. https://doi.org/10.1007/s11121-019-01048-8

Ford, J. H., II, D. K., Wise, M., \& Oliver, K. A. (2011). Measuring sustainability within the veterans administration mental health system redesign initiative. Quality Management in Health Care, 20(4), 263. https://doi.org/10.1097/QMH.0b013e3182314b20

Grubaugh, A. L., Zinzow, H. M., Paul, L., Egede, L. E., \& Frueh, B. C. (2011). Trauma exposure and posttraumatic stress disorder in adults with severe mental illness: A critical review. Clinical Psychology Review, 31(6), 883-899. https://doi.org/10.1016/j.cpr.2011.04.003

Hacker, K., Mechanic, R., \& Santos, P. (2014). Accountable care in the safety net: a case study of the Cambridge Health Alliance. New York (NY): Commonwealth Fund.

Haine-Schlagel, R., Brookman-Frazee, L., Janis, B., \& Gordon, J. (2013). Evaluating a learning collaborative to implement evidence-informed engagement strategies in community-based services for young children. In Child \& Youth Care Forum (Vol. 42, No. 5, pp. 457-473). Springer US. https://doi.org/10.1007/s10566-013-9210-5

Hanson, R. F., Saunders, B. E., Ralston, E., Moreland, A. D., Peer, S. O., \& Fitzgerald, M. M. (2019). Statewide implementation of child trauma-focused practices using the communitybased learning collaborative model. Psychological Services, 16(1), 170. http://doi.org/10.1037/ser0000319 
Haque, S. N. (2021). Telehealth Beyond COVID-19. Psychiatric Services, 72(1), 100-103. https://doi.org/10.1176/appi.ps.202000368

Harris, M.E., \& Fallot, R.D. (2001). Using trauma theory to design service systems. Jossey-Bass. https://psycnet.apa.org/record/2001-00826-000

Helseth, S. A., Peer, S. O., Are, F., Korell, A. M., Saunders, B. E., Schoenwald, S. K., Chapman, J.E. \& Hanson, R. F. (2020). Sustainment of Trauma-Focused and Evidence-Based Practices Following Learning Collaborative Implementation. Administration and Policy in Mental Health and Mental Health Services Research, 1-12. https://doi.org/10.1007/s10488020-01024-3

Hearld, L. R., Bleser, W. K., Alexander, J. A., \& Wolf, L. J. (2016). A systematic review of the literature on the sustainability of community health collaboratives. Medical Care Research and Review, 73(2), 127-181. https://doi.org/10.1177/1077558715607162

Hoagwood, K. E., Olin, S. S., Horwitz, S., McKay, M., Cleek, A., Gleacher, A., Lewandowski, E., Nadeem, E., Acri, M., Chor, K., Kuppinger, A., Burton, G., Weiss, D., Frank, S., Finnerty, M., Bradbury, D., Woodlock, K., \& Hogan, M. (2014). Scaling up evidencebased practices for children and families in New York State: toward evidence-based policies on implementation for state mental health systems. Journal of Clinical Child \& Adolescent Psychology, 43(2), 145-157. https://doi.org/10.1080/15374416.2013.869749

Kelly, R. J., \& Hearld, L. R. (2020). Burnout and leadership style in behavioral health care: A literature review. The journal of behavioral health services \& research, 1-20. https://doi.org/10.1007/s11414-019-09679-Z

Kilo, C. M. (1998). A framework for collaborative improvement: Lessons from the Institute for Healthcare Improvement's Breakthrough Series. Quality Management in Health Care, 6, 
$1-14$.

http://www.centertrt.org/content/docs/Intervention_Documents/Intervention_Materials/O

SNAP/Framework_for_Collaborative_Improvement.pdf

Kongstvedt, P. R. (2013). Essentials of managed health care. Jones \& Bartlett Publishers.

Kopelovich, S. L., Hughes, M., Monroe-DeVita, M. B., Peterson, R., Cather, C., \& Gottlieb, J. (2019). Statewide implementation of cognitive behavioral therapy for psychosis through a learning collaborative model. Cognitive and Behavioral Practice, 26(3), 439-452. https://doi.org/10.1016/j.cbpra.2018.08.004

Lang, J. M., Campbell, K., Shanley, P., Crusto, C. A., \& Connell, C. M. (2016). Building capacity for trauma-informed care in the child welfare system: Initial results of a statewide implementation. Child Maltreatment, 21(2), 113-124. https://doi.org/10.1177/1077559516635273

Lang, J. M., Franks, R. P., Epstein, C., Stover, C., \& Oliver, J. A. (2015). Statewide dissemination of an evidence-based practice using Breakthrough Series Collaboratives. Children and Youth Services Review, 55, 201-209. https://doi.org/10.1016/j.childyouth.2015.06.005

Lang, J. M., Campbell, K., Shanley, P., Crusto, C. A., \& Connell, C. M. (2016). Building capacity for trauma-informed care in the child welfare system: Initial results of a statewide implementation. Child Maltreatment, 21(2), 113-124. https://doi.org/10.1177/1077559516635273

Levy-Carrick, N. C., Lewis-O'Connor, A., Rittenberg, E., Manosalvas, K., Stoklosa, H. M., \& Silbersweig, D. A. (2019). Promoting health equity through trauma-informed care: 
critical role for physicians in policy and program development. Family \& Community Health, 42(2), 104-108. https://doi.org/10.1097/FCH.0000000000000214

Lewis, C.C., Klasnja, P., Powell, B., Tuzzio, L., Jones, S., Walsh-Bailey, C., \& Weiner, B. (2018). From classification to causality: advancing understanding of mechanisms of change in implementation science. Frontiers in Public Health, 6, 136. https://doi.org/10.3389/fpubh.2018.00136

Lin, L. A., Casteel, D., Shigekawa, E., Weyrich, M. S., Roby, D. H., \& McMenamin, S. B. (2019). Telemedicine-delivered treatment interventions for substance use disorders: A systematic review. Journal of Substance Abuse Treatment, 101, 38-49. https://doi.org/10.1016/j.jsat.2019.03.007

Linehan, M. M. (2018). Cognitive-behavioral treatment of borderline personality disorder. Guilford Publications.

Lloyd, J., Houston, R., \& McGinnis, T. (2015). Medicaid accountable care organization programs: State profiles. Hamilton, NJ: Center for Health Care Strategies. https://housingis.org/sites/default/files/Medicaid-Accountable-Care-OrganizationPrograms-State-Profiles.pdf

LoSavio, S. T., Dillon, K. H., Murphy, R. A., Goetz, K., Houston, F., \& Resick, P. A. (2019). Using a learning collaborative model to disseminate cognitive processing therapy to community-based agencies. Behavior Therapy, 50(1), 36-49. https://doi.org/10.1016/j.beth.2018.03.007

MacDonald-Wilson, K. L., Hutchison, S. L., Karpov, I., Wittman, P., \& Deegan, P. E. (2017). A successful implementation strategy to support adoption of decision making in mental 
health services. Community Mental Health Journal, 53(3), 251-256.

https://doi.org/10.1007/s10597-016-0027-1

Markiewicz, J., Ebert, L., Ling, D., Amaya-Jackson, L., \& Kisiel, C. (2006). Learning collaborative toolkit. Los Angeles, California: National Center for Child Traumatic Stress

McLeod, B. D., Cox, J. R., Jensen-Doss, A., Herschell, A., Ehrenreich-May, J., \& Wood, J. J. (2018). Proposing a mechanistic model of clinician training and consultation. Clinical Psychology: Science and Practice, 25(3), e12260. https://doi.org/10.1111/cpsp.12260

Michie S., Carey R.N., Johnston M., Rothman A.J., de Bruin M., Kelly M.P., \& Connell, L.E. (2018). From theory-inspired to theory-based interventions: a protocol for developing and testing a methodology for linking behaviour change techniques to theoretical mechanisms of action. Annals of Behavioral Medicine 52, 501-512. https://doi.org/10.1007/s12160$\underline{016-9816-6}$

Nadeem, E., Olin, S.S., Hill, L.C., Hoagwood, K., \& Horwitz, S. (2014). Learning collaboratives in mental health: Used but untested. Psychiatric Services, 65(9), 1088-1099. https://doi.org/10.1176/appi.ps.201300229

Nadeem, E., Olin, S. S., Hill, L. C., Hoagwood, K. E., \& Horwitz, S. M. (2013). Understanding the components of quality improvement collaboratives: a systematic literature review. The Milbank Quarterly, 91(2), 354-394.

https://onlinelibrary.wiley.com/doi/pdf/10.1111/milq.12016?casa_token=_dj1FNZrZDkA AAAA:Rc6ofXsTzf4uz8h_FKuCKG0ElXOuLkMYXovnMRa3MpiYndbj46BWWiW4 WOvmlAlgBrX_MCdzhTMBNsKJ

Nadeem, E., Weiss, D., Olin, S. S., Hoagwood, K. E., \& Horwitz, S. M. (2016). Using a theoryguided learning collaborative model to improve implementation of EBPs in a state 
children's mental health system: A pilot study. Administration and Policy in Mental Health and Mental Health Services Research, 43(6), 978-990. https://doi.org/10.1007/s10488-016-0735-4

Najavits, L. (2002). Seeking Safety: A treatment manual for PTSD and substance abuse. Guilford Publications.

Nease, D. E., Nutting, P. A., Graham, D. G., Dickinson, W. P., Gallagher, K. M., \& JeffcottPera, M. (2010). Sustainability of depression care improvements: success of a practice change improvement collaborative. The Journal of the American Board of Family Medicine, 23(5), 598-605. https://doi.org/10.3122/jabfm.2010.05.090212

Nembhard, I. M. (2009). Learning and improving in quality improvement collaboratives: which collaborative features do participants value most?. Health Services Research, 44(2p1), 359-378. https://doi.org/10.1111/j.1475-6773.2008.00923.x

Noroña, C. R., \& Acker, M. L. (2016). Implementation and sustainability of child-parent psychotherapy: The role of reflective consultation in the learning collaborative model. Infant Mental Health Journal, 37(6), 701-716. https://doi.org/10.1002/imhj.21607

Peduzzi, P., Concato, J., Kemper, E., Holford, T. R., \& Feinstein, A. R. (1996). A simulation study of the number of events per variable in logistic regression analysis. Journal of Clinical Epidemiology, 49(12), 1373-1379. https://doi.org/10.1016/S0895$\underline{4356(96) 00236-3}$

Powell, B. J., \& Beidas, R. S. (2016). Advancing implementation research and practice in behavioral health systems. Administration and Policy in Mental Health, 43, 825-833. https://doi.org/10.1007/s10488-016-0762-1 
Powell, B. J., Fernandez, M. E., Williams, N. J., Aarons, G. A., Beidas, R. S., Lewis, C. C., ... \& Weiner, B. J. (2019). Enhancing the impact of implementation strategies in healthcare: a research agenda. Frontiers in Public Health, 7, 3. https://doi.org/10.3389/fpubh.2019.00003

Powell, B. J., Waltz, T. J., Chinman, M. J., Damschroder, L. J., Smith, J. L., Matthieu, M. M., Proctor, E.K., \& Kirchner, J. E. (2015). A refined compilation of implementation strategies: results from the Expert Recommendations for Implementing Change (ERIC) project. Implementation Science, 10(1), 21. https://doi.org/10.1186/s13012-015-0209-1

Proctor, E. K., Powell, B. J., \& McMillen, J. C. (2013). Implementation strategies: recommendations for specifying and reporting. Implementation Science, 8(1), 139. https://doi.org/10.1186/1748-5908-8-139

Proctor, E., Silmere, H., Raghavan, R., Hovmand, P., Aarons, G., Bunger, A., Griffey, R. \& Hensley, M. (2011). Outcomes for implementation research: conceptual distinctions, measurement challenges, and research agenda. Administration and Policy in Mental Health and Mental Health Services Research, 38(2), 65-76. https://doi.org/10.1007/s10488-010-0319-7

Raghavan, R., Bright, C. L., \& Shadoin, A. L. (2008). Toward a policy ecology of implementation of evidence-based practices in public mental health settings. Implementation Science, 3(1), 26. https://doi.org/10.1186/1748-5908-3-26

Reeves, E. (2015). A synthesis of the literature on trauma-informed care. Issues in Mental Health Nursing, 36(9), 698-709. https://doi.org/10.3109/01612840.2015.1025319

Resick, P. A., Monson, C. M., \& Chard, K. M. (2016). Cognitive processing therapy for PTSD: A comprehensive manual. Guilford Publications. 
Rutkowski, B. A., Gallon, S., Rawson, R. A., Freese, T. E., Bruehl, A., Crèvecoeur-MacPhail, D., ... \& Cotter, F. (2010). Improving client engagement and retention in treatment: The Los Angeles County experience. Journal of Substance Abuse Treatment, 39(1), 78-86. https://doi.org/10.1016/j.jsat.2010.03.015

Schouten, L. M., Hulscher, M. E., van Everdingen, J. J., Huijsman, R., \& Grol, R. P. (2008). Evidence for the impact of quality improvement collaboratives: systematic review. BMJ, 336(7659), 1491-1494. https://doi.org/10.1136/bmj.39570.749884.BE

Steinwachs, D. M. (1997). Consumer outcomes and managed behavioral health care: research priorities. Managed Care: Quality Improvement in Behavioral Health, 312-335.

Stephan, S. H., Connors, E. H., Arora, P., \& Brey, L. (2013). A learning collaborative approach to training school-based health providers in evidence-based mental health treatment. Children and Youth Services Review, 35(12), 1970-1978. https://doi.org/10.1016/j.childyouth.2013.09.008

Tyree, P. T., Lind, B. K., \& Lafferty, W. E. (2006). Challenges of using medical insurance claims data for utilization analysis. American Journal of Medical Quality, 21(4), 269275. https://doi.org/10.1177/1062860606288774 


\section{Appendix A. Tables and Figures}

Table 1.

Demographic characteristics of individuals in service (percentage of sample in parentheses)

\begin{tabular}{|c|c|c|}
\hline Characteristic & $\begin{array}{l}\text { Mental Health } \\
(n=6,330)\end{array}$ & $\begin{array}{c}\text { Substance Use } \\
(n=1,920)\end{array}$ \\
\hline \multicolumn{3}{|l|}{ Individuals Served } \\
\hline Adults (ages 18+) & $4,925(77.80)$ & $1,774(92.40)$ \\
\hline Children (ages 0-17) & $1,405(22.20)$ & $146(7.60)$ \\
\hline \multicolumn{3}{|l|}{ Race } \\
\hline White/Caucasian & $6,021(95.12)$ & $1,817(94.64)$ \\
\hline Black/African-American & $158(2.50)$ & $52(2.71)$ \\
\hline Asian/Asian-American & $13(0.21)$ & $3(0.16)$ \\
\hline Native American/Alaska Native & $17(0.27)$ & $5(0.26)$ \\
\hline Other/Not reported & $121(1.91)$ & $43(2.24)$ \\
\hline Non-Hispanic & $6,220(98.26)$ & $1893(98.59)$ \\
\hline Female & $3,574(56.46)$ & $953(49.64)$ \\
\hline \multicolumn{3}{|l|}{ Number of claims reimbursed } \\
\hline Individual Therapy & $10,807(73.04)$ & $3,238(68.18)$ \\
\hline Group Therapy & $934(6.31)$ & $780(16.42)$ \\
\hline Family Therapy & $245(1.66)$ & $7(0.15)$ \\
\hline Medical/Psychiatric Visit & $2,809(18.99)$ & $581(12.23)$ \\
\hline \multirow[t]{2}{*}{ Evaluation } & $0(0.00)$ & $143(3.01)$ \\
\hline & Mean (SD) & Mean $(\mathrm{SD})$ \\
\hline Age at date of service & $39.08 \overline{(12.67)}$ & $36.36 \overline{(10.70)}$ \\
\hline Amount billed per claim (USD) & $111.11(62.49)$ & $87.28(57.26)$ \\
\hline Amount paid by MCO per claim (USD) & $73.77(30.44)$ & $74.62(30.60)$ \\
\hline
\end{tabular}


Table 2.

Descriptive statistics for study outcome variables

\begin{tabular}{|c|c|c|c|c|c|c|c|c|c|c|c|c|c|c|c|c|}
\hline & $\mathbf{T}_{1}$ & $\mathbf{T}_{2}$ & $\mathbf{T}_{3}$ & $\mathbf{T}_{4}$ & $\mathbf{T}_{5}$ & $\mathbf{T}_{6}$ & $\mathbf{T}_{7}$ & $\mathbf{T}_{8}$ & $\mathbf{T}_{9}$ & $\mathbf{T}_{10}$ & $\mathbf{T}_{11}$ & $\mathbf{T}_{12}$ & $\mathbf{T}_{13}$ & $\mathbf{T}_{14}$ & $\mathbf{T}_{15}$ & $\mathbf{T}_{51 / 56}$ \\
\hline Screening & 41.12 & 46.78 & 52.79 & 54.88 & 58.15 & 57.64 & 59.95 & 63.79 & 64.07 & 70.68 & 74.46 & 77.00 & 75.22 & 76.06 & 93.27 & 86.53 \\
\hline SD & 42.98 & 41.87 & 41.97 & 40.60 & 41.99 & 40.71 & 38.76 & 40.80 & 39.24 & 36.63 & 34.71 & 33.35 & 32.79 & 34.61 & 11.95 & 26.43 \\
\hline$n$ & 18 & 19 & 22 & 21 & 22 & 21 & 21 & 22 & 22 & 22 & 20 & 20 & 20 & 19 & 14 & 19 \\
\hline New Trained & 24.43 & 14.85 & 12.24 & 8.90 & 5.40 & 9.05 & 7.29 & 6.10 & 11.62 & 10.43 & 4.29 & 6.33 & 9.85 & 7.06 & 7.57 & \\
\hline $\mathrm{SD}$ & 42.22 & 30.53 & 17.54 & 18.20 & 8.70 & 16.93 & 10.07 & 6.66 & 12.18 & 19.17 & 5.12 & 6.09 & 12.19 & 6.14 & 10.16 & \\
\hline$n$ & 21 & 20 & 21 & 20 & 20 & 21 & 21 & 21 & 21 & 21 & 21 & 21 & 20 & 18 & 14 & \\
\hline Total Trained & 24.43 & 38.57 & 50.81 & 59.29 & 64.43 & 73.48 & 80.76 & 86.86 & 98.48 & 108.90 & 113.19 & 119.52 & 128.90 & 134.95 & 140.00 & 154.50 \\
\hline $\mathrm{SD}$ & 42.22 & 70.60 & 79.23 & 96.28 & 103.59 & 107.79 & 111.75 & 116.63 & 124.57 & 136.89 & 136.16 & 136.00 & 144.48 & 148.16 & 150.87 & 157.02 \\
\hline$n$ & 21 & 21 & 21 & 21 & 21 & 21 & 21 & 21 & 21 & 21 & 21 & 21 & 21 & 21 & 21 & 18 \\
\hline Confidence & 15.77 & 19.71 & 31.78 & 42.97 & 46.15 & 36.00 & 45.78 & 46.92 & 48.23 & 47.82 & 53.96 & 56.52 & 63.23 & 66.16 & 80.52 & 34.56 \\
\hline SD & 15.51 & 13.24 & 25.25 & 34.00 & 35.95 & 30.23 & 34.19 & 29.32 & 31.03 & 30.54 & 29.57 & 31.38 & 29.07 & 30.71 & 17.66 & 29.56 \\
\hline$n$ & 17 & 18 & 19 & 21 & 20 & 20 & 20 & 20 & 20 & 20 & 21 & 20 & 20 & 19 & 15 & 15 \\
\hline Trauma Diag. & 10.13 & 9.68 & 10.08 & 10.05 & 10.01 & 9.74 & 9.94 & 9.89 & 9.83 & 9.80 & 9.81 & 9.79 & 9.78 & 9.75 & 9.27 & 9.44 \\
\hline SD & 8.67 & 8.87 & 8.67 & 8.66 & 8.65 & 8.73 & 8.66 & 8.66 & 8.67 & 8.71 & 8.75 & 8.79 & 8.84 & 8.88 & 8.81 & 10.52 \\
\hline$n$ & 21 & 21 & 21 & 21 & 21 & 21 & 21 & 21 & 21 & 21 & 21 & 21 & 21 & 21 & 21 & 19 \\
\hline Retention & 62.10 & 62.63 & 62.64 & 62.63 & 60.57 & 60.49 & 60.45 & 60.40 & 60.32 & 60.42 & 60.44 & 60.32 & 60.37 & 60.37 & 60.37 & 56.81 \\
\hline SD & 35.43 & 35.11 & 35.09 & 35.06 & 37.43 & 37.47 & 37.57 & 37.60 & 37.62 & 37.71 & 37.80 & 37.92 & 38.19 & 38.09 & 38.09 & 66.26 \\
\hline$n$ & 21 & 21 & 21 & 21 & 21 & 21 & 21 & 21 & 21 & 21 & 21 & 21 & 21 & 21 & 21 & 19 \\
\hline Density & 10.06 & 10.02 & 9.99 & 9.94 & 9.88 & 9.83 & 9.49 & 9.73 & 9.64 & 9.63 & 9.59 & 9.57 & 9.54 & 9.49 & 9.44 & 8.81 \\
\hline SD & 9.03 & 9.01 & 9.00 & 8.97 & 8.94 & 8.93 & 8.95 & 8.91 & 8.86 & 8.83 & 8.91 & 8.96 & 9.01 & 9.03 & 9.10 & 10.56 \\
\hline$n$ & 21 & 21 & 21 & 21 & 21 & 21 & 21 & 21 & 21 & 21 & 21 & 21 & 21 & 21 & 21 & 19 \\
\hline Progress rating & 1.59 & 1.86 & 2.21 & 2.50 & 2.68 & 2.89 & 3.02 & 3.25 & 3.43 & 3.68 & 3.84 & 4.02 & 4.09 & 4.29 & 4.67 & \\
\hline $\mathrm{SD}$ & 0.33 & 0.32 & 0.63 & 0.72 & 0.76 & 0.79 & 0.76 & 0.77 & 0.66 & 0.63 & 0.54 & 0.52 & 0.50 & 0.44 & 0.36 & \\
\hline$n$ & 22 & 22 & 22 & 22 & 22 & 22 & 22 & 22 & 22 & 22 & 22 & 22 & 22 & 21 & 15 & \\
\hline
\end{tabular}

Note. Screening = percentage of individuals in service screened for trauma; New Trained = number of new staff trained in traumainformed care; Total Trained = cumulative number of staff trained in trauma-informed care; Confidence = percentage of staff endorsing high confidence using trauma-informed care; Trauma Diag. = percentage of all codes billed that are trauma-related; Retention = percentage of trauma service length (in days) out of service for all diagnoses; Density = percentage of units billed for trauma diagnostic codes out of all possible diagnostic codes 
Table 3.

Average TLC milestone completion as a percentage of possible action steps

\begin{tabular}{llll}
\hline Milestone & $n_{\text {addressed }}$ & $M(\mathrm{SD})$ & Range \\
\hline 1. Laying the Foundation & 22 & $85.15(14.68)$ & $40.00-100.00$ \\
2. Informing Staff and Patients & 22 & $75.91(17.90)$ & $40.00-100.00$ \\
3. Internal Staff Training & 22 & $98.48(7.11)$ & $66.67-100.00$ \\
4. Developing Workflows & 22 & $88.64(15.39)$ & $50.00-100.00$ \\
5. Chart Documentation & 21 & $79.55(29.52)$ & $0.00-100.00$ \\
6. Measuring Progress & 21 & $72.73(27.29)$ & $0.00-100.00$ \\
7. Learning Community Aims and Outcomes & 22 & $86.36(18.28)$ & $33.33-100.00$ \\
8. Clinical Challenges & 20 & $73.86(37.38)$ & $0.00-100.00$ \\
9. Unexpected Operational Challenges & 22 & $68.18(32.49)$ & $16.67-100.00$ \\
10. Supporting Staff & 21 & $65.45(25.58)$ & $0.00-100.00$ \\
11. Nurturing Care & 21 & $64.39(32.24)$ & $0.00-100.00$ \\
12. Expanding Implementation & 21 & $61.36(31.45)$ & $0.00-100.00$
\end{tabular}


Table 4.

PDSA grade and PDSA quality rating frequencies by provider

\begin{tabular}{cl}
\hline PDSA Grade/Quality Rating & \multicolumn{1}{c}{$n(\%)$} \\
\hline $\mathrm{A}+/ 9$ & $0(0.00)$ \\
$\mathrm{A} / 8$ & $6(27.27)$ \\
$\mathrm{A}-/ 7$ & $1(4.55)$ \\
$\mathrm{B}+/ 6$ & $2(9.09)$ \\
$\mathrm{B} / 5$ & $4(18.18)$ \\
$\mathrm{B}-/ 4$ & $4(18.18)$ \\
$\mathrm{C}+/ 3$ & $3(13.64)$ \\
$\mathrm{C} / 2$ & $1(4.55)$ \\
$\mathrm{C}-/ 1$ & $1(4.55)$
\end{tabular}


Table 5.

Pearson correlations among study variables at end of TLC $\left(T_{15}\right)$

\begin{tabular}{|c|c|c|c|c|c|c|c|c|c|}
\hline Variable & 1 & 2 & 3 & 4 & 5 & 6 & 7 & 8 & 9 \\
\hline $\begin{array}{l}\text { 1. Trauma Symptom } \\
\text { Screening Rate }\end{array}$ & -- & & & & & & & & \\
\hline $\begin{array}{l}\text { 2. Total Staff } \\
\text { Trained }\end{array}$ & -.08 & -- & & & & & & & \\
\hline $\begin{array}{l}\text { 3. Staff High } \\
\text { Confidence Rate }\end{array}$ & .03 & .41 & -- & & & & & & \\
\hline $\begin{array}{l}\text { 4. Trauma Diagnosis } \\
\text { Rate }\end{array}$ & -.22 & -.03 & -.43 & -- & & & & & \\
\hline $\begin{array}{l}\text { 5. Service Unit } \\
\text { Density Rate }\end{array}$ & -.23 & -.03 & -.40 & $.97 * *$ & -- & & & & \\
\hline $\begin{array}{l}\text { 6. Service Retention } \\
\text { Rate }\end{array}$ & -.06 & -.26 & -.15 & .13 & .09 & -- & & & \\
\hline $\begin{array}{l}\text { 7. TLC Progress } \\
\text { Rate }\end{array}$ & -.46 & .39 & .10 & .32 & .34 & -.24 & -- & & \\
\hline $\begin{array}{l}\text { 8. TLC Milestone } \\
\text { Completion Rate }\end{array}$ & -.33 & .06 & -.06 & .09 & .10 & -.21 & .50 & -- & \\
\hline 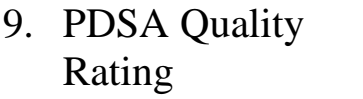 & .01 & -.40 & -.05 & .20 & .14 & -.09 & -.03 & -.20 & -- \\
\hline
\end{tabular}

Note. Correlations for each of these variables were calculated at the same time point, $\mathrm{T}_{15}$ (i.e., end of the active implementation/TLC period).

$* *=$ statistically significant at $\mathrm{p}<.001$ 
Table 6.

Repeated Measures ANOVA results for changes in TLC outcomes across time

\begin{tabular}{|c|c|c|c|c|c|c|c|}
\hline Source & $S S$ & $M S$ & $d f$ & $d f_{\text {error }}$ & $F$ & $p$ & $\Pi_{p}^{2}$ \\
\hline Time x Screening & 49513.15 & 11778.54 & 4.20 & 88.28 & $8.90 * *$ & $<.001$ & 0.30 \\
\hline Time x Confidence & 78619.14 & 16604.80 & 4.74 & 99.43 & $17.19 * *$ & $<.001$ & 0.45 \\
\hline $\begin{array}{l}\text { Time x Trauma } \\
\text { Diagnosis }\end{array}$ & 12.84 & 5.34 & 2.40 & 48.06 & 0.98 & .394 & 0.05 \\
\hline Time x Density & 8.24 & 5.84 & 1.41 & 22.59 & 1.39 & .263 & 0.05 \\
\hline Time $\mathrm{x}$ Retention & 274.79 & 234.63 & 1.17 & 23.42 & 1.08 & .322 & 0.05 \\
\hline
\end{tabular}

Note. Greenhouse-Geisser correction was applied to each test of within-subjects effects because Mauchly's test of sphericity was violated; Screening = percentage of individuals in service that were screened for trauma; Training = cumulative number of staff trained in trauma-informed care; Confidence $=$ percentage of staff endorsing high confidence using trauma-informed care; Trauma Diagnosis = percentage of all codes billed that are trauma-related; Density = percentage of units billed for trauma diagnostic codes out of all possible diagnostic codes, and Retention $=$ percentage of trauma service length (in days) out of service for all diagnoses.

$* *=$ statistically significant at $\mathrm{p}<.001$ 
Table 7.

Pairwise comparison of means for changes in trauma symptom screening rates over time

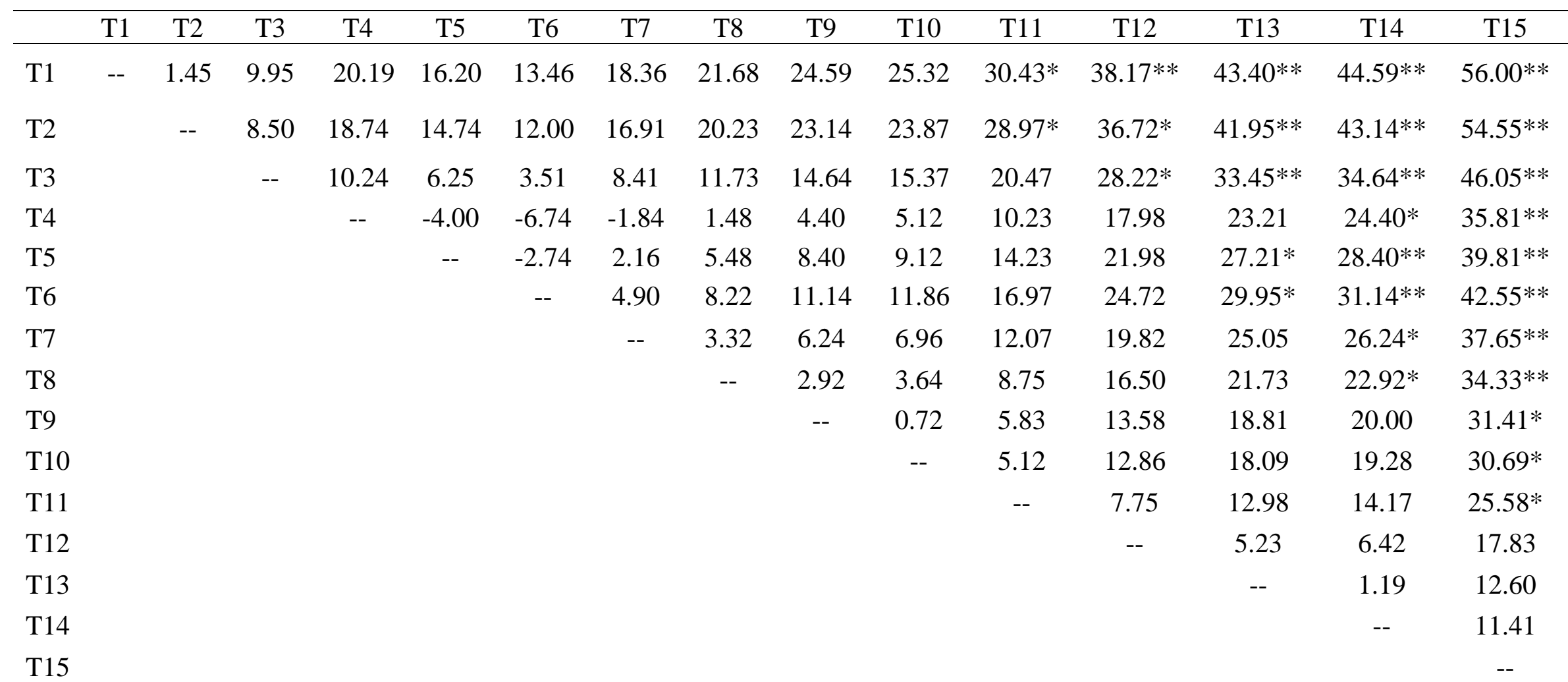

Note. Mean differences are calculated as $\mathrm{T}_{\mathrm{x} \text {-axis }}-\mathrm{T}_{\mathrm{y} \text {-axis; }}$; trauma symptom screening rate $=$ percentage of individuals in service that were screened for trauma

$*=$ statistically significant at $\mathrm{p}<.05$

$* *=$ statistically significant at $\mathrm{p}<.001$ 
Table 8.

Pairwise comparisons of means for changes in staff trauma-informed care confidence rates over time

\begin{tabular}{|c|c|c|c|c|c|c|c|c|c|c|c|c|c|c|c|}
\hline & $\mathrm{T} 1$ & $\mathrm{~T} 2$ & T3 & $\mathrm{T} 4$ & T5 & T6 & $\mathrm{T} 7$ & $\mathrm{~T} 8$ & T9 & T10 & T11 & T12 & T13 & T14 & $\mathrm{T} 15$ \\
\hline $\mathrm{T} 1$ & -- & 3.82 & 10.10 & 13.00 & 15.46 & 16.74 & 16.91 & 21.10 & 21.38 & 27.99 & $31.88^{*}$ & $31.37 *$ & $30.11 *$ & $31.36^{*}$ & $49.34 * *$ \\
\hline $\mathrm{T} 2$ & & -- & 6.27 & 9.17 & 11.64 & 12.92 & 13.09 & 17.28 & 17.56 & 24.17 & 28.05 & $27.55^{*}$ & 26.29 & $27.53^{*}$ & $45.51 * *$ \\
\hline T3 & & & -- & 2.90 & 5.36 & 6.64 & 6.82 & 11.01 & 11.29 & 17.90 & 21.78 & 21.27 & 20.01 & 21.26 & $39.24 *$ \\
\hline $\mathrm{T} 4$ & & & & -- & 2.46 & 3.74 & 3.92 & 8.11 & 8.38 & 14.99 & 18.88 & 18.37 & 17.11 & 18.36 & $36.34 *$ \\
\hline T5 & & & & & -- & 1.28 & 1.45 & 5.64 & 5.92 & 12.53 & 16.42 & 15.91 & 14.65 & 15.90 & 33.88 \\
\hline T6 & & & & & & -- & 0.18 & 4.36 & 4.64 & 11.25 & 15.14 & 14.63 & 13.37 & 14.62 & 32.60 \\
\hline $\mathrm{T} 7$ & & & & & & & -- & 4.19 & 4.47 & 11.08 & 14.96 & 14.46 & 13.20 & 14.45 & $32.43 *$ \\
\hline $\mathrm{T} 8$ & & & & & & & & -- & 0.28 & 6.89 & 10.77 & 10.27 & 9.01 & 10.26 & 28.24 \\
\hline T9 & & & & & & & & & -- & 6.61 & 10.49 & 9.99 & 8.73 & 9.98 & 27.96 \\
\hline $\mathrm{T} 10$ & & & & & & & & & & -- & 3.89 & 3.38 & 2.12 & 3.37 & 21.35 \\
\hline $\mathrm{T} 11$ & & & & & & & & & & & -- & -0.51 & -1.77 & -0.52 & 17.46 \\
\hline $\mathrm{T} 12$ & & & & & & & & & & & & -- & -1.26 & -0.01 & 17.97 \\
\hline $\mathrm{T} 13$ & & & & & & & & & & & & & -- & 1.25 & 19.23 \\
\hline $\mathrm{T} 14$ & & & & & & & & & & & & & & -- & 17.98 \\
\hline T15 & & & & & & & & & & & & & & & -- \\
\hline
\end{tabular}

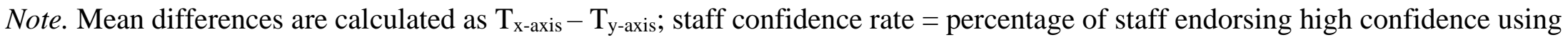
trauma-informed care

*= statistically significant at $\mathrm{p}<.05$

$* *=$ statistically significant at $\mathrm{p}<.001$ 
Table 9.

Fixed Effects of Time and TICC Status on Skills and Attitudes

\begin{tabular}{|c|c|c|c|c|c|c|c|}
\hline Source & $d f_{\text {Num }}$ & $d f_{D e n}$ & $F$ & $p$ & $-2 L L$ & $\begin{array}{l}X^{2} \\
\text { likelihood ratio }\end{array}$ & $\begin{array}{l}X^{2} \\
p \text {-value }\end{array}$ \\
\hline \multicolumn{8}{|l|}{ Staff Confidence } \\
\hline Intercept & 1 & 26.01 & $103.23^{* *}$ & $<.001$ & 2416.56 & & \\
\hline Time & 14 & 116.03 & $10.68 * *$ & $<.001$ & & & \\
\hline Intercept & 1 & 26.40 & $105.37 * *$ & $<.001$ & 2415.53 & 1.03 & .598 \\
\hline Time & 14 & 110.10 & $9.86 * *$ & $<.001$ & & & \\
\hline TICC 2018 & 2 & 37.00 & 0.81 & .454 & & & \\
\hline Intercept & 1 & 32.88 & $75.62^{* *}$ & $<.001$ & 2416.49 & 0.07 & .966 \\
\hline Time & 14 & 115.77 & $10.64 * *$ & $<.001$ & & & \\
\hline TICC 2019 & 2 & 37.99 & 0.04 & .962 & & & \\
\hline \multicolumn{8}{|l|}{ TLC Milestones } \\
\hline Intercept & 1 & 23.17 & $290.24 * *$ & $<.001$ & 740.49 & & \\
\hline Time & 14 & 120.00 & $41.39 * *$ & $<.001$ & & & \\
\hline Intercept & 1 & 24.01 & $320.63^{* *}$ & $<.001$ & 732.77 & $7.72^{*}$ & .021 \\
\hline Time & 14 & 115.39 & $43.49 * *$ & $<.001$ & & & \\
\hline TICC 2018 & 2 & 43.34 & $4.42 *$ & .018 & & & \\
\hline Intercept & 1 & 26.59 & $255.51 * *$ & $<.001$ & 739.25 & 1.24 & .538 \\
\hline Time & 14 & 117.07 & $42.17 * *$ & $<.001$ & & & \\
\hline TICC 2019 & 2 & 42.86 & 0.81 & .451 & & & \\
\hline \multicolumn{8}{|l|}{ Progress Ratings } \\
\hline Intercept & 1 & 29.23 & $1172.14 * *$ & $<.001$ & 205.13 & & \\
\hline Time & 14 & 110.66 & $52.99 * *$ & $<.001$ & & & \\
\hline Intercept & 1 & 29.33 & $1141.60 * *$ & $<.001$ & 203.66 & 1.47 & .480 \\
\hline Time & 14 & 118.11 & $55.51 * *$ & $<.001$ & & & \\
\hline TICC 2018 & 2 & 56.35 & 0.95 & .394 & & & \\
\hline Intercept & 1 & 36.03 & $942.40 * *$ & $<.001$ & 200.38 & 4.75 & .093 \\
\hline Time & 14 & 104.86 & $51.85^{* *}$ & $<.001$ & & & \\
\hline TICC_2019 & 2 & 55.74 & 2.82 & .068 & & & \\
\hline \multicolumn{8}{|l|}{ PDSA Quality } \\
\hline Intercept & 1 & 330 & $1986.46 * *$ & $<.001$ & 1435.71 & & \\
\hline Intercept & 1 & 330 & $1851.36^{* *}$ & $<.001$ & 1442.28 & $6.57 *$ & .037 \\
\hline TICC 2018 & 2 & 330 & 0.72 & .488 & & & \\
\hline Intercept & 1 & 330 & $1137.65^{* *}$ & $<.001$ & 1413.14 & 22.57 & $<.001$ \\
\hline TICC 2019 & 2 & 330 & $11.68 * *$ & $<.001$ & & & \\
\hline
\end{tabular}

Note. Staff confidence $=$ percentage of staff endorsing high confidence in using trauma-informed care; TLC milestones = cumulative number of goals addressed by a providers' quality improvement team; progress ratings = provider-reported progress reaching implementation goals; PDSA quality $=$ objective ratings of engagement and success using PDSA cycles; TICC 2018 = Trauma Informed Care Center status in 2018; TICC 2019 = Trauma Informed Care Center status in 2019

$*=$ statistically significant at $\mathrm{p}<.05 ; * *=$ statistically significant at $\mathrm{p}<.001$ 
Figure 1.

Breakthrough Series Collaborative Model

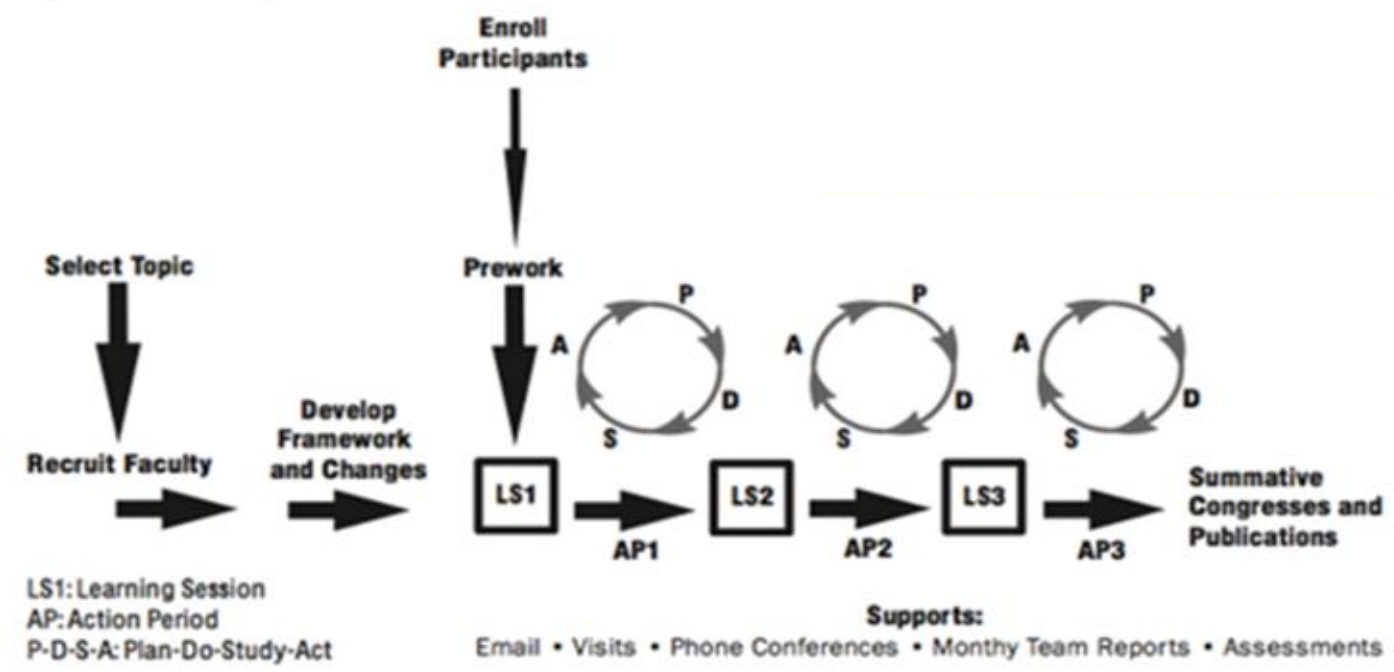




\section{Appendix B. Measures \& Sources of Data}

\section{TLC Workbook Template}

\section{BHARP Trauma Institute Learning Collaborative}

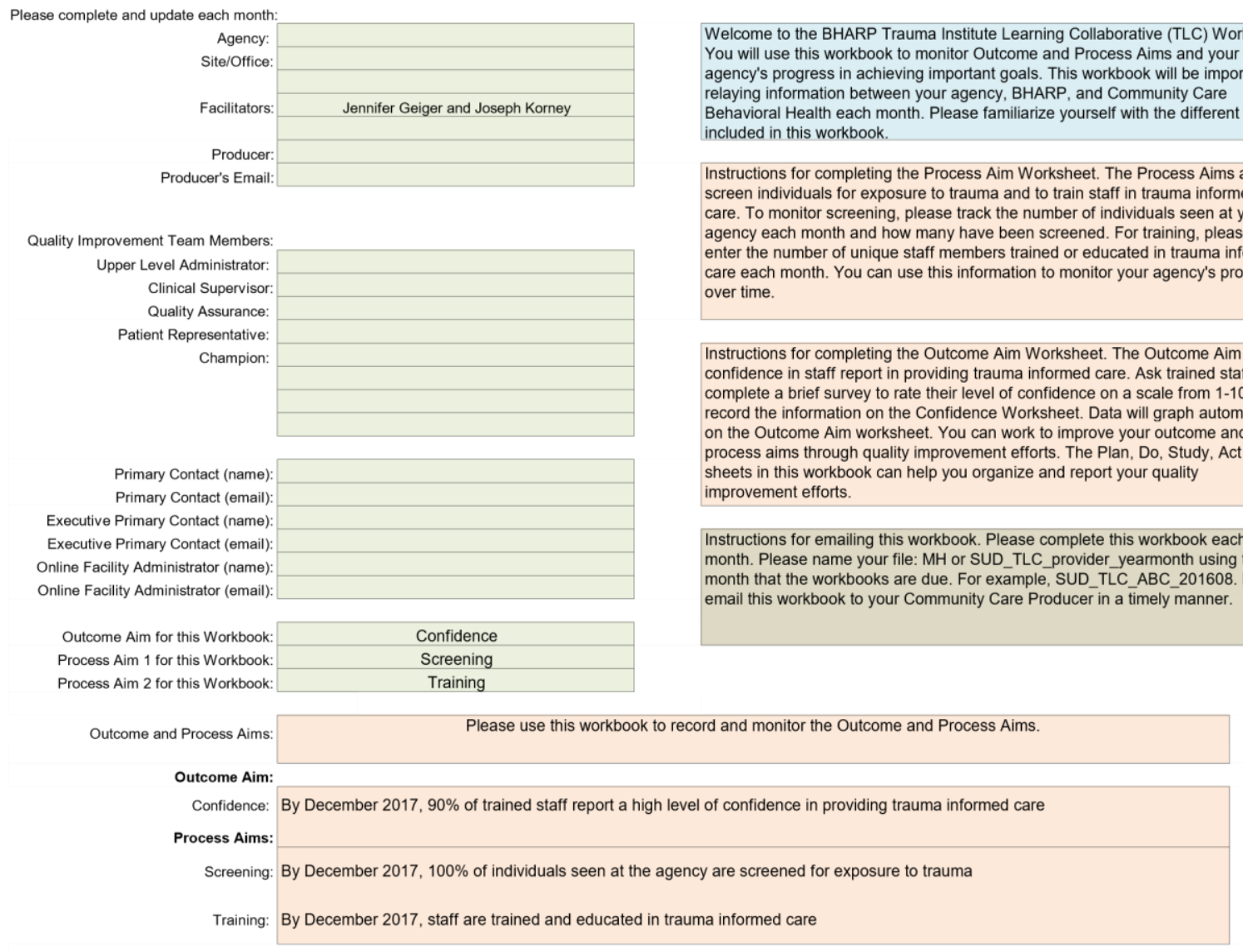

\section{BHARP Trauma Institute Learning Collaborative Milestone Chart}

Below you will find milestones around training and implementing trauma informed care at your agency. You should accomplish all the milestones in order to implement with fidelity. Each milestone is followed by questions and suggestions (indicated by the

$" \square "$ symbol) that will help guide your implementation planning. Not all questions or suggestions will be relevant to your implementation - focus on those that are pertinent to your organization. Utilize the blank lines for notes or additional items on which your program needs to focus. 


\begin{tabular}{|c|c|c|c|}
\hline Stage & $\begin{array}{c}\text { Person } \\
\text { Responsible }\end{array}$ & Trauma Informed Care Milestones & Completed? \\
\hline \multirow{28}{*}{ 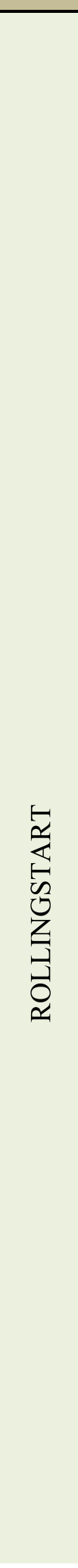 } & \multicolumn{3}{|c|}{ Milestone 1: Lay the Foundation } \\
\hline & & $\begin{array}{l}\text { Why is trauma informed care important to your agency? How can you } \\
\text { convey the importance of this initiative to staff and patients? }\end{array}$ & \\
\hline & & Who will be involved in planning and carrying out the implementation? & \\
\hline & & $\square \square$ Executive Leadership & \\
\hline & & $\square \square$ Clinical/Quality Improvement Leadership & \\
\hline & & $\square \square$ Quality Assurance & \\
\hline & & $\square \square$ Individual in service & \\
\hline & & $\square \square$ Champion & \\
\hline & & & \\
\hline & & $\begin{array}{l}\text { Have you established a Quality Improvement Team (QIT) for this } \\
\text { initiative? }\end{array}$ & \\
\hline & & Have you developed a schedule for regular meetings of the QIT? & \\
\hline & & When will the QIT meet? & \\
\hline & & Have you determined what topics your QIT will cover? & \\
\hline & & $\square \square$ Complete the Organizational Self-Assessment & \\
\hline & & $\begin{array}{l}\square \text { Assess the difference between your organization's current } \\
\text { approach to trauma informed care }\end{array}$ & \\
\hline & & $\begin{array}{l}\square \square \text { Identify areas of standards where competency levels are met } \\
\text { or not met }\end{array}$ & \\
\hline & & $\begin{array}{l}\square \square \text { Make changes to your physical environment to promote a } \\
\text { trauma informed, safe space }\end{array}$ & \\
\hline & & & \\
\hline & & & \\
\hline & \multicolumn{3}{|c|}{ Milestone 2: Informing Staff and Patients } \\
\hline & & $\begin{array}{l}\text { Have you developed a communication plan to let all staff and patients } \\
\text { know about your initiative? }\end{array}$ & \\
\hline & & $\square$ Email announcements & \\
\hline & & $\square$ Internal web communication & \\
\hline & & $\square \square \square$ Provider meetings & \\
\hline & & $\square \square \square$ Health Fair & \\
\hline & & $\square \square \square$ Posters & \\
\hline & & $\square \square \square$ Other? & \\
\hline & & $\begin{array}{l}\text { How can you measure or document success in achieving staff and } \\
\text { patient awareness of the importance of the initiative? }\end{array}$ & \\
\hline
\end{tabular}




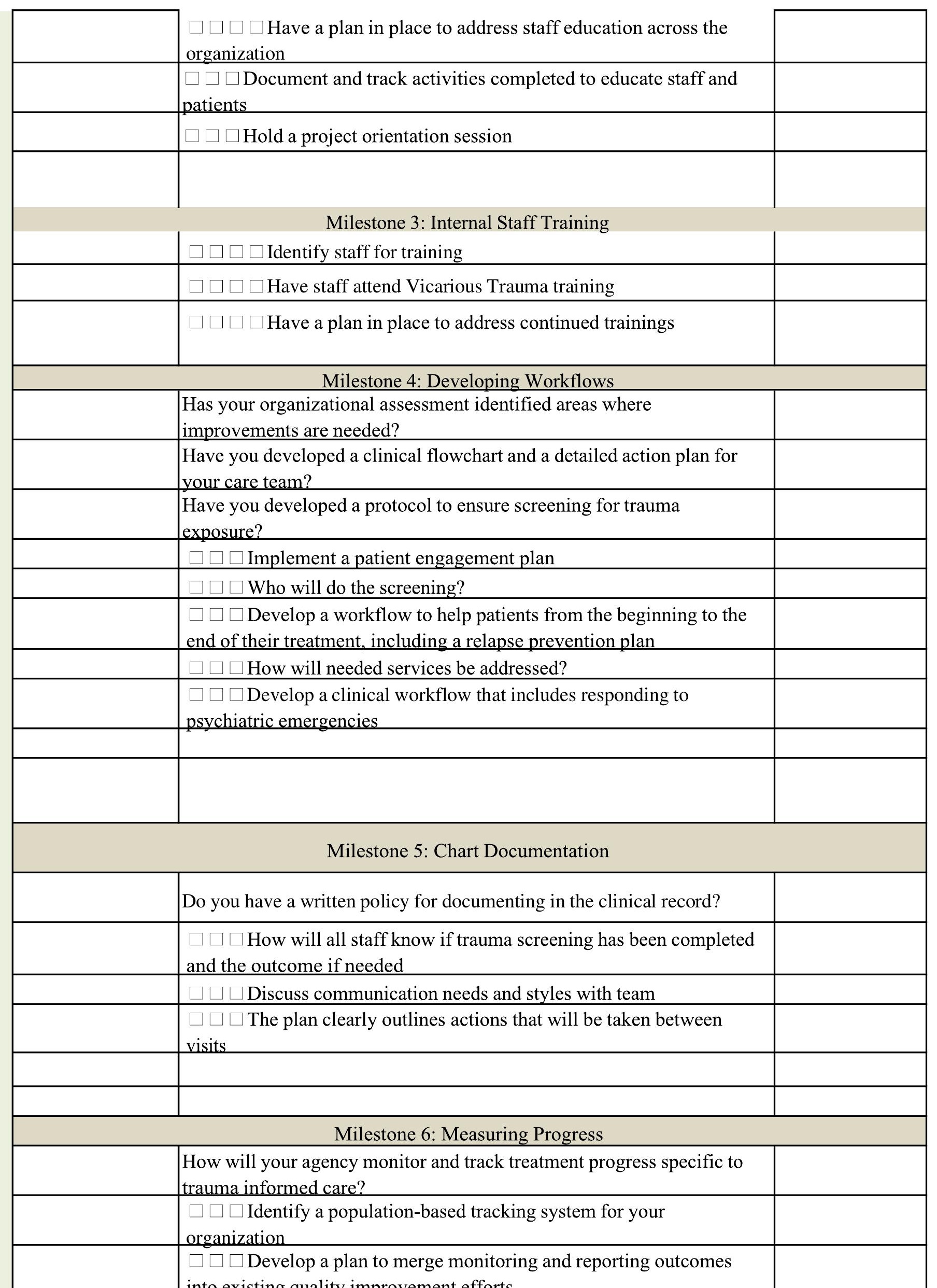




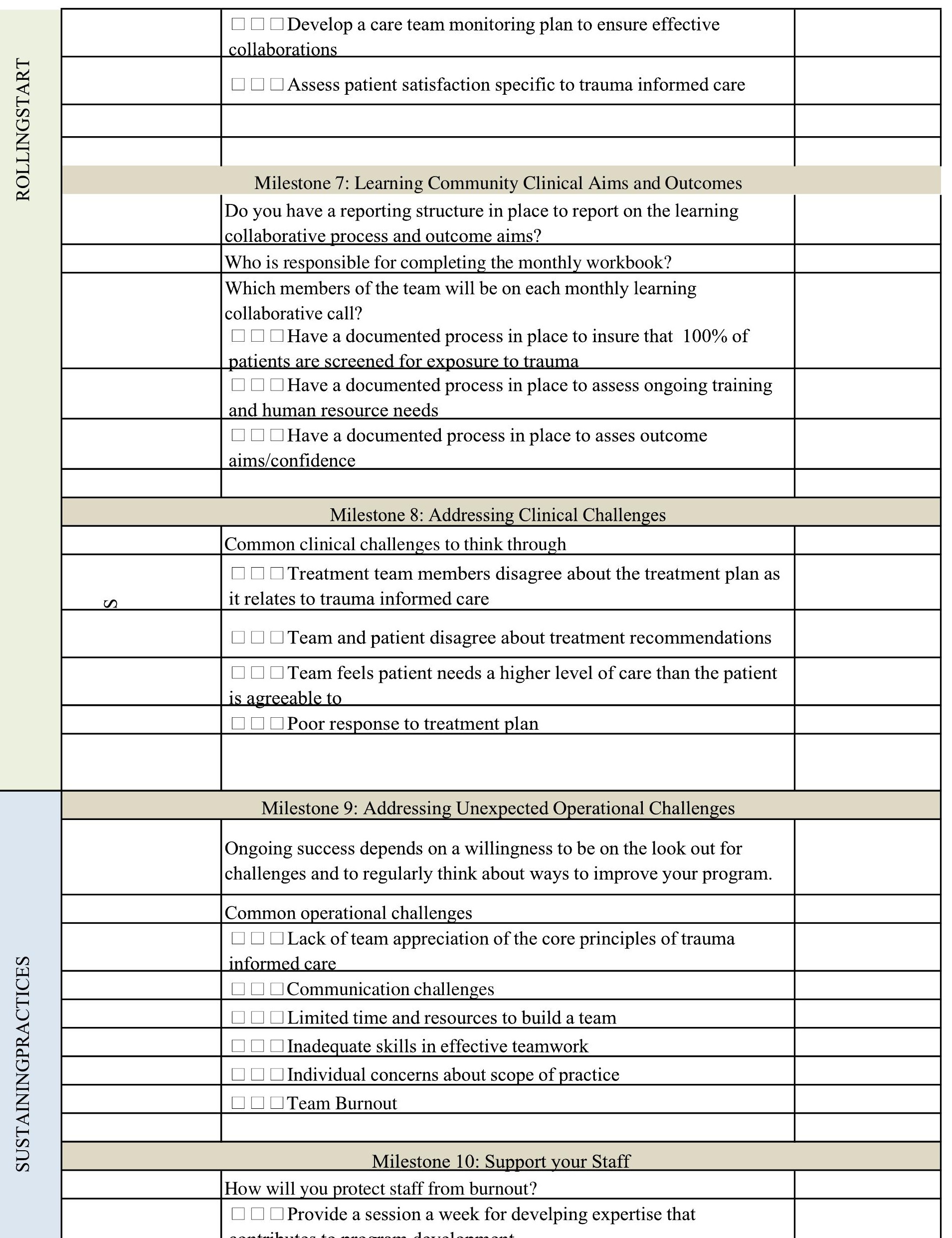




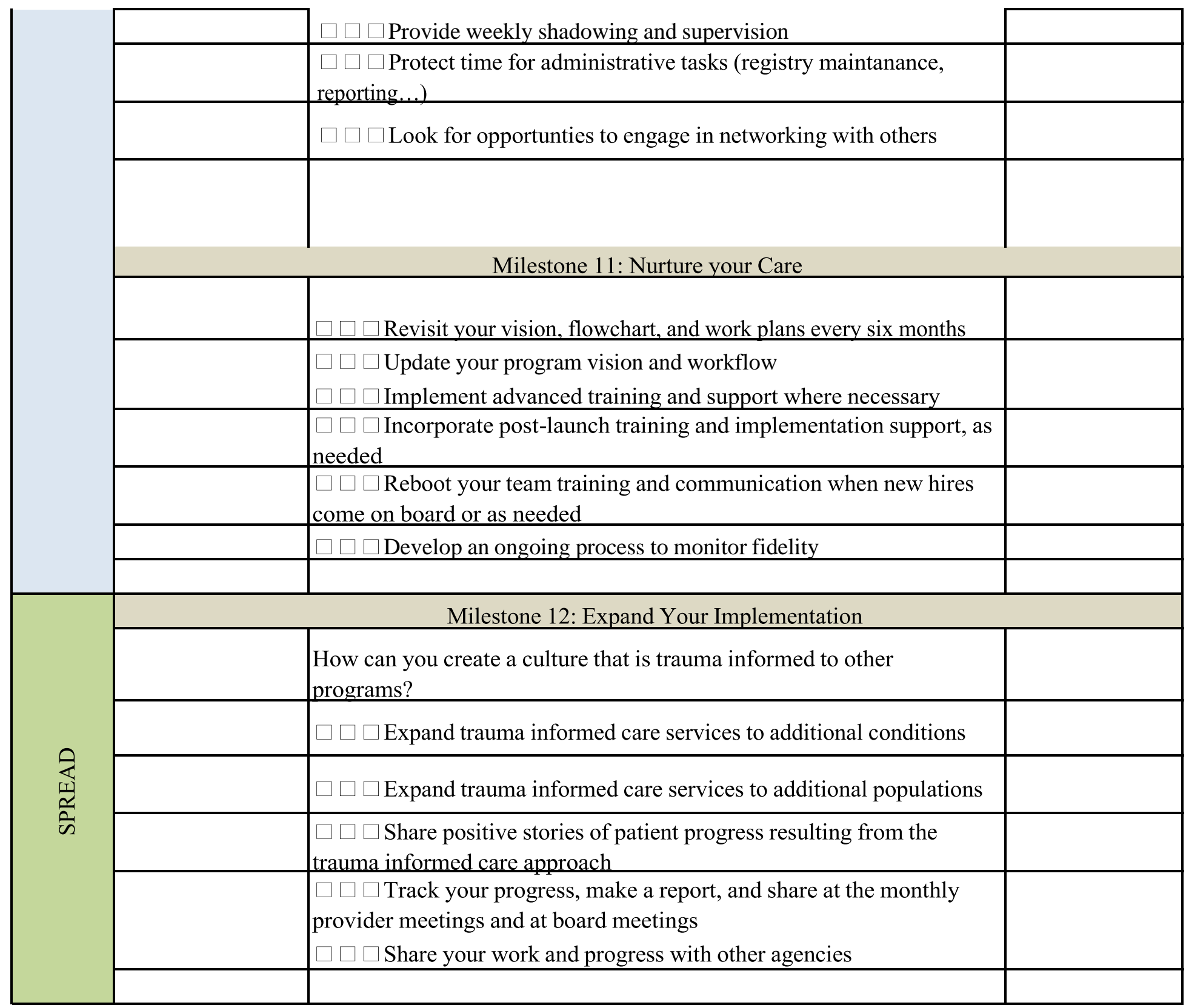




\begin{tabular}{|c|c|c|c|c|c|c|c|c|c|c|c|c|c|c|c|c|}
\hline Assessment: & Aug-16 & Sep-16 & Oct-16 & Nov-16 & Dec-16 & Jan-17 & Feb-17 & Mar-17 & Apr-17 & May-17 & Jun-17 & Jul-17 & Aug-17 & Sep-17 & Oct-17 & Nov-17 \\
\hline \multicolumn{17}{|l|}{ Rating (1-5) } \\
\hline & & & & & & & & & & & & & & & & \\
\hline & & & & & & & & & & & & & & & & \\
\hline & & & & & & & & & & & & & & & & \\
\hline & & & & & & & & & & & & & & & & \\
\hline & Rating: & Definition: & & & Example: & & & & & & & & & & & \\
\hline & 1.0 & \multicolumn{3}{|c|}{ Charter and team established } & \multicolumn{11}{|c|}{ Charter completed and reviewed. Individuals or teams have been assigned but no work has been accomplished. } & \\
\hline & 1.5 & \multicolumn{3}{|c|}{ Planning for the project } & \multicolumn{12}{|c|}{ Organization of project structure has begun (such as resources needed, support work needed, focus, meeting schedule developed). } \\
\hline & 2.0 & \multicolumn{3}{|c|}{ Activity, but no changes } & \multicolumn{12}{|c|}{ Initial cycles for team learning have begun (project planning, measurement, data collection, etc). } \\
\hline & 2.5 & \multicolumn{3}{|c|}{$\begin{array}{l}\text { Changes tested, but no } \\
\text { improvement }\end{array}$} & \multicolumn{12}{|c|}{$\begin{array}{l}\text { Initial cycles for testing changes have begun. Most project goals have a measure established to track progress. Measures are graphically } \\
\text { displayed with targets included. }\end{array}$} \\
\hline & 3.0 & \multicolumn{3}{|c|}{ Modest improvement } & \multicolumn{12}{|c|}{$\begin{array}{l}\text { Successful tests of changes have been completed for some components of the change package related to the team's charter. Some small } \\
\text { scale implementation has been done. }\end{array}$} \\
\hline & 3.5 & \multicolumn{3}{|c|}{ Improvement } & \multicolumn{12}{|c|}{ Testing and implementation continues and additional improvement in project measures toward goals is seen. } \\
\hline & 4.0 & \multicolumn{3}{|c|}{ Significant improvement } & \multicolumn{12}{|c|}{$\begin{array}{l}\text { Expected results achieved for major subsystems. Implementation (training, communication, etc) has begun for the project. Project goals are } \\
50 \% \text { or more complete. }\end{array}$} \\
\hline & 4.5 & \multicolumn{3}{|c|}{ Sustainable improvement } & \multicolumn{12}{|c|}{ Data on key measures begin to indicate sustainability of impact of changes implemented in the system. } \\
\hline & 5.0 & \multicolumn{3}{|c|}{ Outstanding sustainable results } & \multicolumn{12}{|c|}{$\begin{array}{l}\text { Implementation cycles have been completed and all project goals and expected results have been accomplished. Organization changes have } \\
\text { been made to accommodate improvements and to make the project changes permanent. }\end{array}$} \\
\hline & & & & & & & & & & & & & & & & \\
\hline Instructions: & \multirow{2}{*}{\multicolumn{16}{|c|}{ Please enter the rating for your organization for each month in the first row }} \\
\hline & & & & & & & & & & & & & & & & \\
\hline & & & & & & & & & & & & & & & & \\
\hline & & & & & & & & & & & & & & & & \\
\hline & & & & & & & & & & & & & & & & \\
\hline & & & & & & & & & & & & & & & & \\
\hline & & & & & & & & & & & & & & & & \\
\hline & & & & & & & & & & & & & & & & \\
\hline & & & & & & & & & & & & & & & & \\
\hline & & & & & & & & & & & & & & & & \\
\hline & & & & & & & & & & & & & & & & \\
\hline & & & & & & & & & & & & & & & & \\
\hline & & & & & & & & & & & & & & & & \\
\hline
\end{tabular}


Process Aim 1:

Trauma Exposure Screening

1. Total no. of patients that month:

2. No. of those patients screened that month:

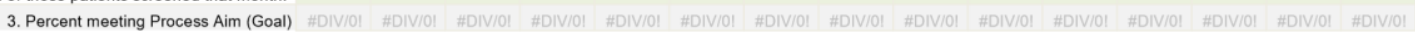

Instructions: Please enter the number of individuals seen at the agency that month in row 1 [the blue row] Please enter the number of individuals screened for trauma exposure in row 2 the green row]. Please do not enter or delete information in row 3 [the gray row]-- this row computes automatically

\section{Process Aim: 1). By December 2017, $100 \%$ of individuals are screened for exposure to trauma}

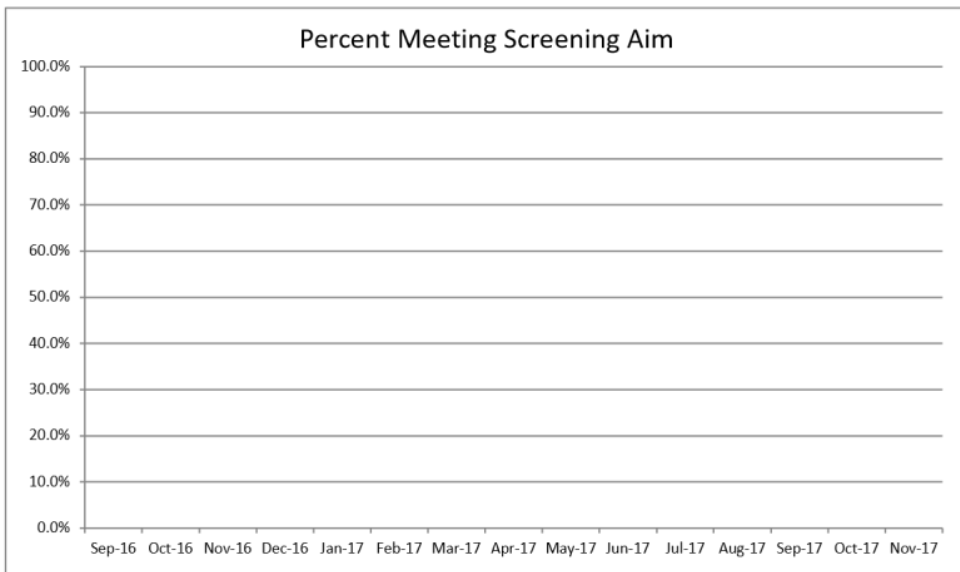

please scroll right to view PA 2: 


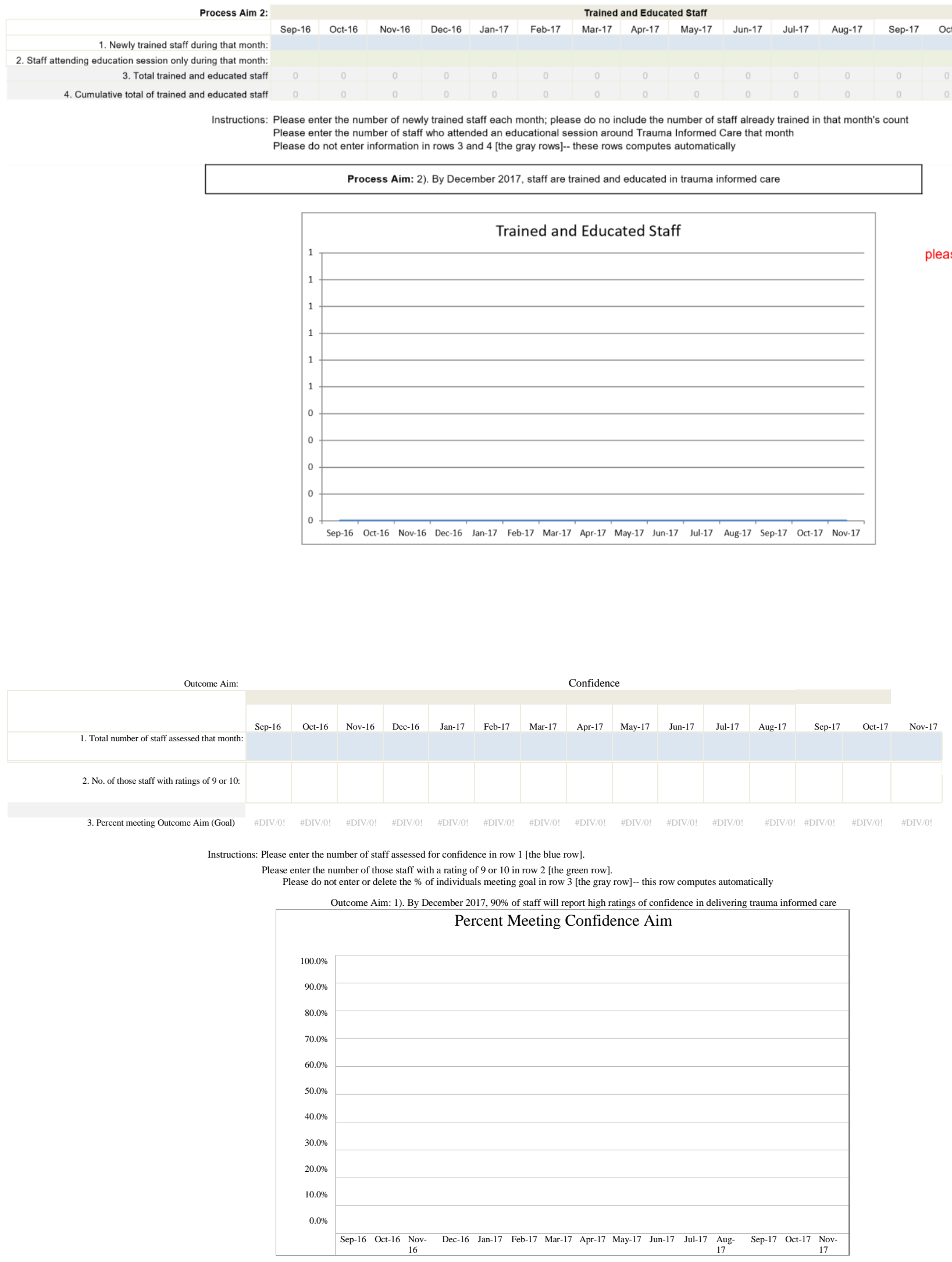


BHARP Trauma Institute Learning Collaborative (TLC) Confidence Survey

Name or ID:

Date:

Instructions: This survey is to be completed by staff members at organizations participating in the Trauma Institute

1. How confident are you in providing trauma informed care to the individuals you serve?

$\square 1 \quad \square 2 \quad \square 3 \quad \square 4 \quad \square 5 \quad \square 6 \quad \square 7 \quad \square 8 \quad \square 9 \quad \square 10$

Not at all confident Somewhat confident $\quad$ Extremely confident 
Outcome Aim:

Confidence

Total no. of assessments:

0

Total assessed that month Total meeting the Outcome Air

Pera

Instructions:

Ask each trained staff member
to complete a confidence

survey.

Enter survey data values (1-10)

into that montris collum

If you would like to track
responses over time, please
assign an ID number to sta

assign an ID number to staff a
enter data on the correct row

each month . THIS
OPTIONAL.
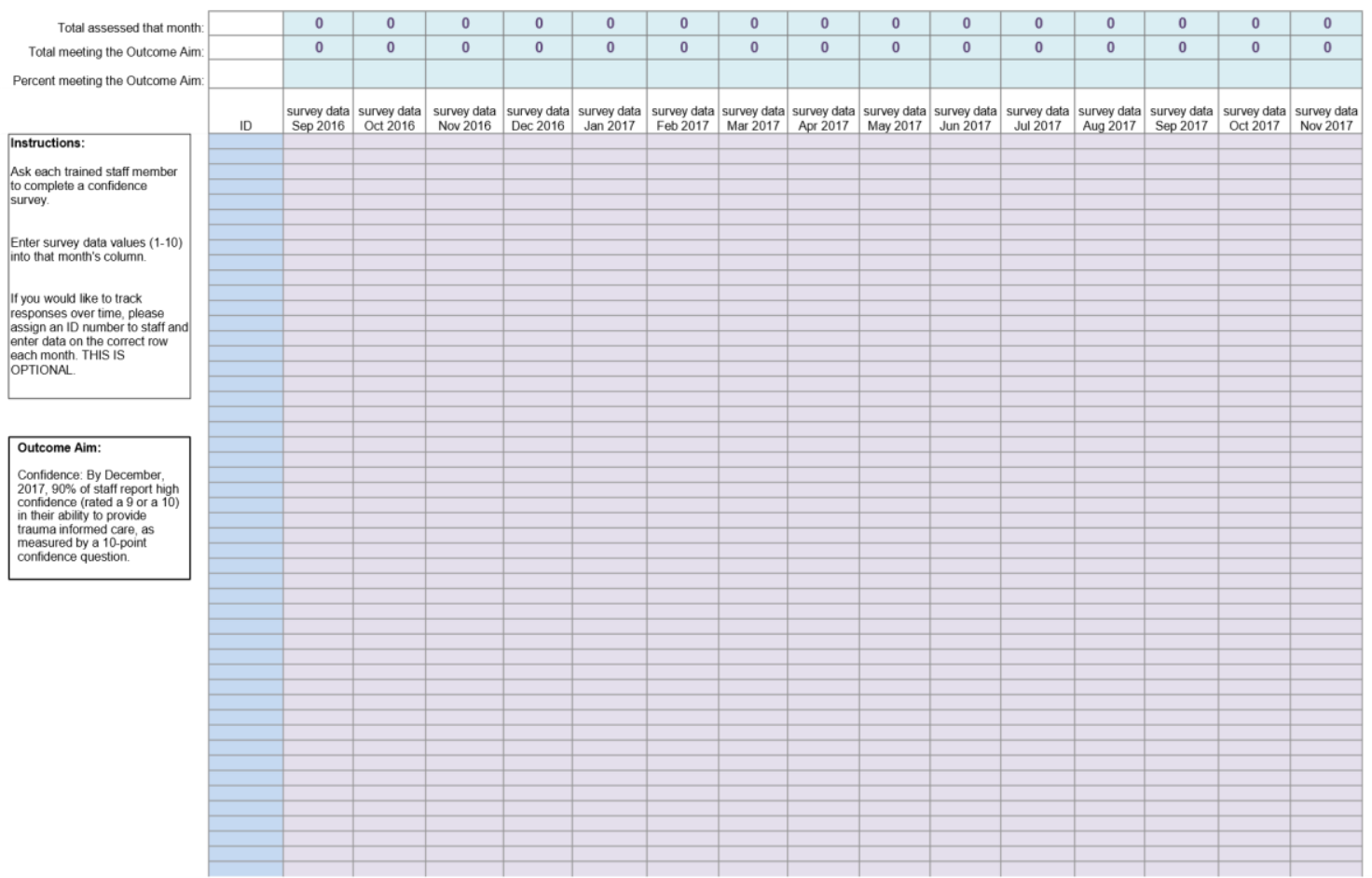
PDSA Cycle September

BEGIN DATE:

DATE COMPLETED:

Milestone/Fidelity:

PLAN

What is your objective?

What question(s) do you want to answer on this PDSA cycle?

What do you predict will happen?

What is your specific plan?

DO

Did you carry out your plan?

$\square$ Yes

No

Summarize what happened.

STUDY

What did you find out? Compare your observation/data to your predictions and summarize what you learned.

ACT

What is your next logical step?

Move on and develop a new PDSA cycle based on what you learned in this one. 


\section{Trauma-Informed Care Organizational Application}

Organization/Program:

Site:

Date completed:

Team member completing this assessment: $\quad \square$ Administration $\quad \square$ Clinical Staff $\square$ Non-Clinical Staff

\begin{tabular}{|c|c|c|c|c|c|}
\hline \multirow[t]{2}{*}{ Data Source } & \multicolumn{5}{|c|}{ Status } \\
\hline & 0 & 1 & 2 & 3 & 4 \\
\hline $\begin{array}{l}\text { A Staff Interviews } \\
\text { B Consumer/Caregiver } \\
\text { Interviews } \\
\text { C Review of } \\
\text { Policies/Procedures } \\
\text { D Client Record Review } \\
\text { E Treatment Team or } \\
\text { Debriefing } \\
\text { F Observation } \\
\text { G All of the Above }\end{array}$ & $\begin{array}{l}\text { No data, } \\
\text { No plan }\end{array}$ & $\begin{array}{l}\text { Plan has been } \\
\text { developed but } \\
\text { not } \\
\text { implemented }\end{array}$ & $\begin{array}{l}\text { Plan has been } \\
\text { implemented }\end{array}$ & $\begin{array}{l}\text { Plan has been } \\
\text { implemented } \\
\text { and } \\
\text { data have been } \\
\text { gathered } \\
\text { regarding } \\
\text { implementation }\end{array}$ & $\begin{array}{l}\text { Plan has been } \\
\text { implemented } \\
\text { and } \\
\text { revised based on } \\
\text { feedback/data } \\
\text { regarding } \\
\text { implementation }\end{array}$ \\
\hline
\end{tabular}

\begin{tabular}{|c|c|c|c|c|c|c|c|}
\hline \multicolumn{8}{|c|}{ DOMAIN I. Competent Trauma-Informed Organizational Practice } \\
\hline & \multirow{2}{*}{$\begin{array}{c}\text { Data Source } \\
\text { Enter all that } \\
\text { apply } \\
\text { A B C D E F G }\end{array}$} & \multicolumn{5}{|c|}{ Status } & \multirow[t]{2}{*}{ Comments/Next Steps } \\
\hline & & 0 & 1 & 2 & 3 & 4 & \\
\hline $\begin{array}{l}\text { 1. Agency leadership at all levels express } \\
\text { commitment to implementing TI Care. }\end{array}$ & & $\square$ & $\square$ & $\square$ & $\square$ & $\square$ & \\
\hline $\begin{array}{l}\text { 2. Agency staff at all levels express } \\
\text { commitment to implementing TI Care. }\end{array}$ & & $\square$ & $\square$ & $\square$ & $\square$ & $\square$ & \\
\hline $\begin{array}{l}\text { 3. Agency leadership has addressed } \\
\text { cultural and policy barriers, externally } \\
\text { and internally, that may impede } \\
\text { implementation. }\end{array}$ & & $\square$ & $\square$ & $\square$ & $\square$ & $\square$ & \\
\hline $\begin{array}{l}\text { 4. The agency has standardized and } \\
\text { systematic approaches for compiling } \\
\text { and monitoring data and outcomes. }\end{array}$ & & $\square$ & $\square$ & $\square$ & $\square$ & $\square$ & \\
\hline
\end{tabular}




\begin{tabular}{|c|c|c|c|c|c|}
\hline \multirow[t]{2}{*}{ Data Source } & \multicolumn{5}{|c|}{ Status } \\
\hline & 0 & 1 & 2 & 3 & 4 \\
\hline $\begin{array}{l}\text { A Staff Interviews } \\
\text { B Consumer/Caregiver } \\
\text { Interviews } \\
\text { C Review of } \\
\text { Policies/Procedures } \\
\text { D Client Record Review } \\
\text { E Treatment Team or } \\
\text { Debriefing } \\
\text { F Observation } \\
\text { G All of the Above }\end{array}$ & $\begin{array}{l}\text { No data, } \\
\text { No plan }\end{array}$ & $\begin{array}{l}\text { Plan has been } \\
\text { developed but } \\
\text { not } \\
\text { implemented }\end{array}$ & $\begin{array}{l}\text { Plan has been } \\
\text { implemented }\end{array}$ & $\begin{array}{l}\text { Plan has been } \\
\text { implemented } \\
\text { and } \\
\text { data have been } \\
\text { gathered } \\
\text { regarding } \\
\text { implementation }\end{array}$ & $\begin{array}{l}\text { Plan has been } \\
\text { implemented } \\
\text { and } \\
\text { revised based on } \\
\text { feedback/data } \\
\text { regarding } \\
\text { implementation }\end{array}$ \\
\hline
\end{tabular}

\begin{tabular}{|l|l|l|l|l|l|l|l|l|}
\hline Question & $\begin{array}{c}\text { Data Source } \\
\text { Enter all that } \\
\text { apply }\end{array}$ & \multicolumn{3}{|c|}{ Status } & \multicolumn{3}{|c|}{ Comments/Next Steps } \\
\hline & A B C D E F G & $\mathbf{0}$ & $\mathbf{1}$ & $\mathbf{2}$ & $\mathbf{3}$ & $\mathbf{4}$ & \\
\hline $\begin{array}{l}\text { 5. Organizational incentives are in place } \\
\text { to support staff as changes are made. }\end{array}$ & & $\square$ & $\square$ & $\square$ & $\square$ & $\square$ & \\
\hline $\begin{array}{l}\text { 6. The organization provides the } \\
\text { resources (technology, staffing, and } \\
\text { training) for implementation of TI Care } \\
\text { and the monitoring of data and } \\
\text { outcomes. }\end{array}$ & & $\square$ & $\square$ & $\square$ & $\square$ & $\square$ & & \\
\hline $\begin{array}{l}\text { 7. Formal policies and procedures reflect } \\
\text { language } \\
\text { and practice of trauma-informed care. }\end{array}$ & & $\square$ & $\square$ & $\square$ & $\square$ & $\square$ & & \\
\hline $\begin{array}{l}\text { 8. This organization provides trauma- } \\
\text { informed care training to all new } \\
\text { employees. }\end{array}$ & & $\square$ & $\square$ & $\square$ & $\square$ & $\square$ & & \\
\hline $\begin{array}{l}\text { 9. This organization provides at least } \\
\text { yearly training updates to trauma- } \\
\text { informed care practice for all staff. }\end{array}$ & & $\square$ & $\square$ & $\square$ & $\square$ & $\square$ & & \\
\hline $\begin{array}{l}\text { 10. There are requirements for all staff to } \\
\text { have at least annual training in } \\
\text { cultural competence. }\end{array}$ & & $\square$ & $\square$ & $\square$ & $\square$ & $\square$ & \\
\hline $\begin{array}{l}\text { 11. The agency has a "trauma-informed } \\
\text { care initiative" (e.g., } \\
\text { workgroup/taskforce, trauma } \\
\text { specialist) endorsed by the chief } \\
\text { administrator }\end{array}$ & & $\square$ & $\square$ & $\square$ & $\square$ & $\square$ & & \\
\hline
\end{tabular}




\begin{tabular}{|c|c|c|c|c|c|}
\hline \multirow{2}{*}{$\begin{array}{c}\text { Data Source } \\
\text { Enter all that apply }\end{array}$} & \multicolumn{5}{|c|}{ Status } \\
\hline & 0 & 1 & 2 & 3 & 4 \\
\hline $\begin{array}{l}\text { A Staff Interviews } \\
\text { B Consumer/Caregiver } \\
\text { Interviews } \\
\text { C Review of } \\
\text { Policies/Procedures } \\
\text { D Client Record Review } \\
\text { E Treatment Team or } \\
\text { Debriefing } \\
\text { F Observation } \\
\text { G All of the Above }\end{array}$ & $\begin{array}{l}\text { No data, } \\
\text { No plan }\end{array}$ & $\begin{array}{l}\text { Plan has been } \\
\text { developed but } \\
\text { not } \\
\text { implemented }\end{array}$ & $\begin{array}{l}\text { Plan has been } \\
\text { implemented }\end{array}$ & $\begin{array}{l}\text { Plan has been } \\
\text { implemented } \\
\text { and } \\
\text { data have been } \\
\text { gathered } \\
\text { regarding } \\
\text { implementation }\end{array}$ & $\begin{array}{l}\text { Plan has been } \\
\text { implemented and } \\
\text { revised based on } \\
\text { feedback/data } \\
\text { regarding } \\
\text { implementation }\end{array}$ \\
\hline
\end{tabular}

\begin{tabular}{|c|c|c|c|c|c|c|c|}
\hline \multicolumn{8}{|c|}{ DOMAIN II. Competent Trauma-Informed Clinical and Milieu Practices } \\
\hline \multirow[t]{2}{*}{ Question } & \multirow{2}{*}{$\begin{array}{c}\text { Data Source } \\
\text { Enter all that } \\
\text { apply }\end{array}$} & \multicolumn{5}{|c|}{ Status } & \multirow[t]{2}{*}{ Comments/Next Steps } \\
\hline & & 0 & 1 & 2 & 3 & 4 & \\
\hline $\begin{array}{l}\text { 12. Providers in this agency discuss } \\
\text { resilience and recognize this in } \\
\text { individuals and families. }\end{array}$ & & $\square$ & $\square$ & $\square$ & $\square$ & $\square$ & \\
\hline $\begin{array}{l}\text { 13. The agency has a process in place to } \\
\text { manage conflict within the agency as } \\
\text { well as any conflict that may arise in } \\
\text { a treating relationship. }\end{array}$ & & $\square$ & $\square$ & $\square$ & $\square$ & $\square$ & \\
\hline $\begin{array}{l}\text { 14. The agency has at least one } \\
\text { debriefing process which can be used } \\
\text { at any time there is a serious safety } \\
\text { concern (including any use of } \\
\text { seclusion or restraint) by anyone in } \\
\text { the agency. }\end{array}$ & & $\square$ & $\square$ & $\square$ & $\square$ & $\square$ & \\
\hline $\begin{array}{l}\text { 15. The agency identifies and monitors } \\
\text { the TI Care value of safety. }\end{array}$ & & $\square$ & $\square$ & $\square$ & $\square$ & $\square$ & \\
\hline $\begin{array}{l}\text { 16. The agency identifies and monitors } \\
\text { the TI Care value of trustworthiness. }\end{array}$ & & $\square$ & $\square$ & $\square$ & $\square$ & $\square$ & \\
\hline $\begin{array}{l}\text { 17. The agency identifies and monitors } \\
\text { the TI Care value of choice. }\end{array}$ & & $\square$ & $\square$ & $\square$ & $\square$ & $\square$ & \\
\hline $\begin{array}{l}\text { 18. The agency identifies and monitors } \\
\text { the TI Care value of collaboration. }\end{array}$ & & $\square$ & $\square$ & $\square$ & $\square$ & $\square$ & \\
\hline
\end{tabular}




\begin{tabular}{|c|c|c|c|c|c|}
\hline \multirow{2}{*}{$\begin{array}{c}\text { Data Source } \\
\text { Enter all that apply }\end{array}$} & \multicolumn{5}{|c|}{ Status } \\
\hline & 0 & 1 & 2 & 3 & 4 \\
\hline $\begin{array}{l}\text { A Staff Interviews } \\
\text { B Consumer/Caregiver } \\
\text { Interviews } \\
\text { C Review of } \\
\text { Policies/Procedures } \\
\text { D Client Record Review } \\
\text { E Treatment Team or } \\
\text { Debriefing } \\
\text { F Observation } \\
\text { G All of the Above }\end{array}$ & $\begin{array}{l}\text { No data, } \\
\text { No plan }\end{array}$ & $\begin{array}{l}\text { Plan has been } \\
\text { developed but } \\
\text { not } \\
\text { implemented }\end{array}$ & $\begin{array}{l}\text { Plan has been } \\
\text { implemented }\end{array}$ & $\begin{array}{l}\text { Plan has been } \\
\text { implemented } \\
\text { and } \\
\text { data have been } \\
\text { gathered } \\
\text { regarding } \\
\text { implementation }\end{array}$ & $\begin{array}{l}\text { Plan has been } \\
\text { implemented and } \\
\text { revised based on } \\
\text { feedback/data } \\
\text { regarding } \\
\text { implementation }\end{array}$ \\
\hline
\end{tabular}

\begin{tabular}{|c|c|c|c|c|c|c|c|}
\hline \multirow[t]{2}{*}{ Question } & \multirow{2}{*}{$\begin{array}{l}\text { Data Source } \\
\text { Enter all that } \\
\text { apply }\end{array}$} & \multicolumn{5}{|c|}{ Status } & \multirow[t]{2}{*}{ Comments/Next Steps } \\
\hline & & 0 & 1 & 2 & 3 & 4 & \\
\hline $\begin{array}{l}\text { 19. The agency identifies and monitors } \\
\text { the TI Care value of empowerment. }\end{array}$ & & $\square$ & $\square$ & $\square$ & $\square$ & $\square$ & \\
\hline $\begin{array}{l}\text { 20. The organization promotes the } \\
\text { practice of program improvement } \\
\text { based on quantitative and qualitative } \\
\text { data. }\end{array}$ & & $\square$ & $\square$ & $\square$ & $\square$ & $\square$ & \\
\hline $\begin{array}{l}\text { 21. The organization has a process for } \\
\text { systematic review of the physical and } \\
\text { social environment as it may be } \\
\text { perceived by those who have } \\
\text { experienced trauma. }\end{array}$ & & $\square$ & $\square$ & $\square$ & $\square$ & $\square$ & \\
\hline $\begin{array}{l}\text { 22. All staff who interact with consumers } \\
\text { are a part of a team that allows for } \\
\text { integrated training, supervision, and } \\
\text { peer review in TI Care practices and } \\
\text { principles. }\end{array}$ & & $\square$ & $\square$ & $\square$ & $\square$ & $\square$ & \\
\hline $\begin{array}{l}\text { 23. There are opportunities for staff to } \\
\text { recognize, acknowledge, and address } \\
\text { their vicarious traumatization. }\end{array}$ & & $\square$ & $\square$ & $\square$ & $\square$ & $\square$ & \\
\hline $\begin{array}{l}\text { 24. The program uses specific trauma } \\
\text { screen tool(s) and screening process. }\end{array}$ & & $\square$ & $\square$ & $\square$ & $\square$ & $\square$ & \\
\hline $\begin{array}{l}\text { 25. The program offers trauma-specific, } \\
\text { evidence-based, and evidence- } \\
\text { supported practices. }\end{array}$ & & $\square$ & $\square$ & $\square$ & $\square$ & $\square$ & \\
\hline
\end{tabular}




\begin{tabular}{|c|c|c|c|c|c|}
\hline \multirow[t]{2}{*}{ Data Source } & \multicolumn{5}{|c|}{ Status } \\
\hline & 0 & 1 & 2 & 3 & 4 \\
\hline $\begin{array}{l}\text { A Staff Interviews } \\
\text { B Consumer/Caregiver } \\
\text { Interviews } \\
\text { C Review of } \\
\text { Policies/Procedures } \\
\text { D Client Record Review } \\
\text { E Treatment Team or } \\
\text { Debriefing } \\
\text { F Observation } \\
\text { G All of the Above }\end{array}$ & $\begin{array}{l}\text { No data, } \\
\text { No plan }\end{array}$ & $\begin{array}{l}\text { Plan has been } \\
\text { developed but } \\
\text { not } \\
\text { implemented }\end{array}$ & $\begin{array}{l}\text { Plan has been } \\
\text { implemented }\end{array}$ & $\begin{array}{l}\text { Plan has been } \\
\text { implemented } \\
\text { and } \\
\text { data have been } \\
\text { gathered } \\
\text { regarding } \\
\text { implementation }\end{array}$ & $\begin{array}{l}\text { Plan has been } \\
\text { implemented } \\
\text { and } \\
\text { revised based on } \\
\text { feedback/data } \\
\text { regarding } \\
\text { implementation }\end{array}$ \\
\hline
\end{tabular}

\begin{tabular}{|c|c|c|c|c|c|c|c|}
\hline \multirow[t]{2}{*}{ Question } & \multirow{2}{*}{$\begin{array}{c}\text { Data Source } \\
\text { Enter all that } \\
\text { apply }\end{array}$} & \multicolumn{5}{|c|}{ Status } & \multirow[t]{2}{*}{ Comments/Next Steps } \\
\hline & & 0 & 1 & 2 & 3 & 4 & \\
\hline $\begin{array}{l}\text { 26. Treatment planning and } \\
\text { interventions are individualized, and } \\
\text { developmentally suited to each } \\
\text { person in care. }\end{array}$ & & $\square$ & $\square$ & $\square$ & $\square$ & $\square$ & \\
\hline $\begin{array}{l}\text { 27. Each person in care has a safety or } \\
\text { crisis management plan with } \\
\text { individualized choices for calming } \\
\text { and de-escalation. }\end{array}$ & & $\square$ & $\square$ & $\square$ & $\square$ & $\square$ & \\
\hline $\begin{array}{l}\text { 28. The physical environment is attuned } \\
\text { to safety, calming, and de- } \\
\text { escalation. }\end{array}$ & & $\square$ & $\square$ & $\square$ & $\square$ & $\square$ & \\
\hline $\begin{array}{l}\text { 29. Staff use a strengths-based, person- } \\
\text { centered approach in their } \\
\text { interactions with consumers and } \\
\text { their families. }\end{array}$ & & $\square$ & $\square$ & $\square$ & $\square$ & $\square$ & \\
\hline $\begin{array}{l}\text { 30. Staff has systematic opportunities to } \\
\text { seek support, or assistance from } \\
\text { their peers. }\end{array}$ & & $\square$ & $\square$ & $\square$ & $\square$ & $\square$ & \\
\hline $\begin{array}{l}\text { 31. Staff members have individual } \\
\text { supervision and mentoring to } \\
\text { support trauma-informed practice. }\end{array}$ & & $\square$ & $\square$ & $\square$ & $\square$ & $\square$ & \\
\hline $\begin{array}{l}\text { 32. Staff use the ProQL within their } \\
\text { supervision process to manage and } \\
\text { monitor compassion fatigue. }\end{array}$ & & $\square$ & $\square$ & $\square$ & $\square$ & $\square$ & \\
\hline
\end{tabular}




\begin{tabular}{|c|c|c|c|c|c|}
\hline \multirow[t]{2}{*}{ Data Source } & \multicolumn{5}{|c|}{ Status } \\
\hline & 0 & 1 & 2 & 3 & 4 \\
\hline $\begin{array}{l}\text { A Staff Interviews } \\
\text { B Consumer/Caregiver } \\
\text { Interviews } \\
\text { C Review of } \\
\text { Policies/Procedures } \\
\text { D Client Record Review } \\
\text { E Treatment Team or } \\
\text { Debriefing } \\
\text { F Observation } \\
\text { G All of the Above }\end{array}$ & $\begin{array}{l}\text { No data, } \\
\text { No plan }\end{array}$ & $\begin{array}{l}\text { Plan has been } \\
\text { developed but } \\
\text { not } \\
\text { implemented }\end{array}$ & $\begin{array}{l}\text { Plan has been } \\
\text { implemented }\end{array}$ & $\begin{array}{l}\text { Plan has been } \\
\text { implemented } \\
\text { and } \\
\text { data have been } \\
\text { gathered } \\
\text { regarding } \\
\text { implementation }\end{array}$ & $\begin{array}{l}\text { Plan has been } \\
\text { implemented } \\
\text { and } \\
\text { revised based on } \\
\text { feedback/data } \\
\text { regarding } \\
\text { implementation }\end{array}$ \\
\hline
\end{tabular}

\begin{tabular}{|c|c|c|c|c|c|c|c|}
\hline \multicolumn{8}{|c|}{ Domain III: Consumer and Family Engagement in Trauma-Informed Care } \\
\hline \multirow[t]{2}{*}{ Question } & \multirow{2}{*}{$\begin{array}{l}\text { Data Source } \\
\text { Enter all that } \\
\text { apply } \\
\text { A B C D E F G }\end{array}$} & \multicolumn{5}{|c|}{ Status } & \multirow[t]{2}{*}{ Comments/Next Steps } \\
\hline & & 0 & 1 & 2 & 3 & 4 & \\
\hline $\begin{array}{l}\text { 33. The organization demonstrates in } \\
\text { philosophy and practice intent } \\
\text { toward increasing comfort, } \\
\text { involvement, and collaboration of } \\
\text { consumer \& families. }\end{array}$ & & $\square$ & $\square$ & $\square$ & $\square$ & $\square$ & \\
\hline $\begin{array}{l}\text { 34. The organization regularly trains all } \\
\text { staff on how to engage consumers } \\
\text { and families and monitors extent of } \\
\text { engagement. }\end{array}$ & & $\square$ & $\square$ & $\square$ & $\square$ & $\square$ & \\
\hline $\begin{array}{l}\text { 35. Consumers and families are actively } \\
\text { involved in treatment and discharge } \\
\text { planning and decisions regarding } \\
\text { their transitions in care. }\end{array}$ & & $\square$ & $\square$ & $\square$ & $\square$ & $\square$ & \\
\hline $\begin{array}{l}\text { 36. There are systematic opportunities } \\
\text { for consumer and families to give } \\
\text { feedback to the organization } \\
\text { regarding TI Care values (safety } \\
\text { trustworthiness, choice, } \\
\text { collaboration and empowerment). }\end{array}$ & & $\square$ & $\square$ & $\square$ & $\square$ & $\square$ & \\
\hline
\end{tabular}




\begin{tabular}{|c|c|c|c|c|c|}
\hline \multirow{2}{*}{$\begin{array}{c}\text { Data Source } \\
\text { Enter all that apply }\end{array}$} & \multicolumn{5}{|c|}{ Status } \\
\hline & 0 & 1 & 2 & 3 & 4 \\
\hline $\begin{array}{l}\text { A Staff Interviews } \\
\text { B Consumer/Caregiver } \\
\text { Interviews } \\
\text { C Review of } \\
\text { Policies/Procedures } \\
\text { D Client Record Review } \\
\text { E Treatment Team or } \\
\text { Debriefing } \\
\text { F Observation } \\
\text { G All of the Above }\end{array}$ & $\begin{array}{l}\text { No data, } \\
\text { No plan }\end{array}$ & $\begin{array}{l}\text { Plan has been } \\
\text { developed but } \\
\text { not } \\
\text { implemented }\end{array}$ & $\begin{array}{l}\text { Plan has been } \\
\text { implemented }\end{array}$ & $\begin{array}{l}\text { Plan has been } \\
\text { implemented } \\
\text { and } \\
\text { data have been } \\
\text { gathered } \\
\text { regarding } \\
\text { implementation }\end{array}$ & $\begin{array}{l}\text { Plan has been } \\
\text { implemented and } \\
\text { revised based on } \\
\text { feedback/data } \\
\text { regarding } \\
\text { implementation }\end{array}$ \\
\hline
\end{tabular}

\begin{tabular}{|c|c|c|c|c|c|c|c|}
\hline \multirow[t]{2}{*}{ Question } & \multirow{2}{*}{$\begin{array}{l}\text { Data Source } \\
\text { Enter all that } \\
\text { apply }\end{array}$} & \multicolumn{5}{|c|}{ Status } & \multirow[t]{2}{*}{ Comments/Next Steps } \\
\hline & & 0 & 1 & 2 & 3 & 4 & \\
\hline $\begin{array}{l}\text { 37. Consumers and families serve in a } \\
\text { planning and advisory capacity with } \\
\text { the organization. }\end{array}$ & & $\square$ & $\square$ & $\square$ & $\square$ & $\square$ & \\
\hline $\begin{array}{l}\text { 38. This agency does provide general } \\
\text { education to all clients regarding } \\
\text { trauma-informed principles and } \\
\text { practice. }\end{array}$ & & $\square$ & $\square$ & $\square$ & $\square$ & $\square$ & \\
\hline $\begin{array}{l}\text { 39. This organization has a process to } \\
\text { survey members on satisfaction and } \\
\text { their experience in care and use } \\
\text { survey results to make changes to } \\
\text { how care is delivered. }\end{array}$ & & $\square$ & $\square$ & $\square$ & $\square$ & $\square$ & \\
\hline
\end{tabular}

Based on: Hummer, V. \& Dollard, N. (2010). Creating Trauma-Informed Care Environments: An Organizational SelfAssessment. (part of Creating Trauma-Informed Care Environments curriculum) Tampa FL: University of South Florida. The Department of Child \& Family Studies within the College of Behavioral and Community Sciences. 


\section{Trauma-Informed Care Center Application Rubric}

\begin{tabular}{|c|c|c|c|}
\hline & $\begin{array}{l}\text { Not Implemented or Needs } \\
\text { Improvement }\end{array}$ & Satisfactory & Exemplary \\
\hline $\begin{array}{l}\text { Competent } \\
\text { Trauma- } \\
\text { Informed Care } \\
\text { Organizational } \\
\text { Practice }\end{array}$ & $\begin{array}{l}\text { - Staff consider TIC as a } \\
\text { temporary practice } \\
\text { with an end date } \\
\text { - Leadership does not } \\
\text { embrace TIC but rather } \\
\text { relies on staff to make } \\
\text { changes } \\
\text { - The physical } \\
\text { environment does not } \\
\text { support TIC, lack of self- } \\
\text { soothing rooms/areas } \\
\text { - Lack of collaboration } \\
\text { on TIC efforts }\end{array}$ & $\begin{array}{l}\text { The } \\
\text { organization } \\
\text { acknowledges } \\
\text { that TIC } \\
\text { practice and } \\
\text { culture should } \\
\text { be the norm } \\
\text { - A TIC model is } \\
\text { fully integrated } \\
\text { within this } \\
\text { provider setting } \\
\text { - TIC is spread } \\
\text { throughout the } \\
\text { organization; } \\
\text { ongoing } \\
\text { communication } \\
\text { about changes, } \\
\text { and needed } \\
\text { improvements } \\
\text { are transparent } \\
\text { - Physical } \\
\text { environment } \\
\text { supports TIC } \\
\text { Collaboration } \\
\text { and feedback } \\
\text { from leadership, } \\
\text { staff, and } \\
\text { consumers } \\
\text { inform the TIC } \\
\text { process } \\
\text { Evidence that } \\
\text { the provider } \\
\text { collaborates } \\
\text { with outside } \\
\text { agencies } \\
\text { and/or partners } \\
\text { to maintain a } \\
\text { TIC culture and } \\
\text { status }\end{array}$ & $\begin{array}{l}\text { - TIC is spread } \\
\text { throughout the } \\
\text { organization } \\
\text { - Policies and } \\
\text { practices are trauma } \\
\text { informed } \\
\text { - The organization can } \\
\text { show and/or } \\
\text { highlight how the } \\
\text { treatment } \\
\text { environment is } \\
\text { physically safe. } \\
\text { - The provider has } \\
\text { evidence of } \\
\text { consumer } \\
\text { involvement to } \\
\text { evaluate and } \\
\text { address all types of } \\
\text { safety issues which } \\
\text { may be impacting } \\
\text { the TIC treatment } \\
\text { environment } \\
\text { Change } \\
\text { management plan is } \\
\text { transparent; explore } \\
\text { candidly where } \\
\text { resistance may exist } \\
\text { and tend to } \\
\text { managing it } \\
\text { Process and } \\
\text { outcome measures } \\
\text { around quality } \\
\text { implementation of } \\
\text { TIC is employed } \\
\text { The organization can } \\
\text { provide both the } \\
\text { implementation as } \\
\text { well as sustaining } \\
\text { plan for a TIC } \\
\text { practice }\end{array}$ \\
\hline
\end{tabular}




\begin{tabular}{|c|c|c|c|}
\hline $\begin{array}{l}\text { Competent } \\
\text { Trauma- } \\
\text { Informed } \\
\text { Clinical and } \\
\text { Milieu } \\
\text { Practices }\end{array}$ & $\begin{array}{l}\text { - Caseloads, scheduling } \\
\text { patterns, and record } \\
\text { keeping time } \\
\text { requirements } \\
\text { overwhelm staff } \\
\text { - Lack of training; no } \\
\text { training for non-clinical } \\
\text { staff; lack of refreshers } \\
\text { or updated training }\end{array}$ & $\begin{array}{l}\text { - Organization } \\
\text { recognizes the } \\
\text { costs of } \\
\text { secondary } \\
\text { trauma to } \\
\text { employees } \\
\text { As you select } \\
\text { your model for } \\
\text { TIC, ensure a full } \\
\text { range of } \\
\text { performance } \\
\text { supports is } \\
\text { available to } \\
\text { you. Your } \\
\text { provider should } \\
\text { offer coaching, } \\
\text { consulting, } \\
\text { support for } \\
\text { supervision, and } \\
\text { access in a } \\
\text { variety of ways } \\
\text { Engaging } \\
\text { service } \\
\text { recipients in } \\
\text { learning how to } \\
\text { advocate for } \\
\text { themselves, } \\
\text { how to create } \\
\text { and achieve } \\
\text { self-directed } \\
\text { behavioral } \\
\text { change and to } \\
\text { pace their } \\
\text { learning and } \\
\text { practicing of } \\
\text { healthier } \\
\text { behaviors is } \\
\text { critical } \\
\text { Because TIC is a } \\
\text { relational } \\
\text { process, it helps } \\
\text { when everyone } \\
\text { on your } \\
\text { continuum of } \\
\text { care shares } \\
\text { common } \\
\text { language }\end{array}$ & $\begin{array}{l}\text { The organization } \\
\text { supports the use } \\
\text { of the ProQOL for } \\
\text { all clinical staff at } \\
\text { least yearly } \\
\text { - General TIC } \\
\text { training is } \\
\text { required for all } \\
\text { staff both clinical } \\
\text { and non-clinical } \\
\text { Provider reports } \\
\text { number of hours } \\
\text { in general TIC is } \\
\text { provided, staff } \\
\text { who } \\
\text { participated, } \\
\text { plan for those } \\
\text { who did not and } \\
\text { references for } \\
\text { trainer and } \\
\text { materials used } \\
\text { Programs, plans } \\
\text { and goals for } \\
\text { should also point } \\
\text { to the elements } \\
\text { of recovery and } \\
\text { be strength- } \\
\text { based } \\
\text { Survey staff for } \\
\text { trauma- } \\
\text { treatment tools } \\
\text { and techniques } \\
\text { in which they are } \\
\text { or Evidence- } \\
\text { supported } \\
\text { Practices in TIC } \\
\text { are used } \\
\text { in ongand poll } \\
\text { learning about } \\
\text { those tools and } \\
\text { techniques } \\
\text { - }\end{array}$ \\
\hline
\end{tabular}


- 1-2 Evidence-

Based or

Evidence-

Supported

Practices in TIC

are used

- Stakeholder assessment of $\mathrm{TIC}$ in the workplace is conducted (e.g., ARTIC)
- $\quad$ TIC supervision is used for all clinical staff. All clinical staff must participate in at least monthly clinical supervision. The provider agency should be able to show participation rates and plan for improvement when there is any consistent deficits in supervision participation by supervisor and/or clinical staff.

- Supervisors are trained in TIC supervision and able to participate in a train the trainer model for sustainability.

- The clinical supervisors will monitor fidelity to providing $\mathrm{TIC}$ in general. Where there is a trauma specific treatment approach being applied the supervisor will support outcomes monitoring to ensure best quality of care for the person.

- Stakeholder assessment of TIC in the workplace 
is conducted

(e.g., ARTIC)

\begin{tabular}{|c|c|c|c|}
\hline $\begin{array}{l}\text { Consumer } \\
\text { and Family } \\
\text { Engagement } \\
\text { in Trauma- } \\
\text { Informed Care }\end{array}$ & $\begin{array}{l}\text { - Lack of routine } \\
\text { consumer involvement } \\
\text { in organizational } \\
\text { activities such as } \\
\text { boards, workgroups } \\
\text { - Intrusive intake process; } \\
\text { lack of therapeutic } \\
\text { alliance } \\
\text { - Staff respond to service } \\
\text { recipient feedback in a } \\
\text { negative or dismissive } \\
\text { way; multiple } \\
\text { comments about the } \\
\text { same situation are not } \\
\text { changed }\end{array}$ & $\begin{array}{l}\text { Sporadic } \\
\text { involvement of } \\
\text { consumers in } \\
\text { organizational } \\
\text { activities } \\
\text { - } \quad \text { Treatment plans } \\
\text { are based on } \\
\text { mutual goals; } \\
\text { are strength- } \\
\text { based } \\
\text { Staff help } \\
\text { clients mark } \\
\text { change and } \\
\text { progress } \\
\text { EHR allows for a } \\
\text { recipient-driven } \\
\text { action plan } \\
\text { that is co- } \\
\text { signed by staff } \\
\text { and client }\end{array}$ & $\begin{array}{l}\text { - The organization has } \\
\text { at least one } \\
\text { consumer involved in } \\
\text { an agency activity } \\
\text { each quarter that is } \\
\text { related to TIC } \\
\text { practice } \\
\text { The organization } \\
\text { reports on their } \\
\text { consumer } \\
\text { satisfaction with } \\
\text { results and then } \\
\text { process } \\
\text { improvement plan } \\
\text { that can be } \\
\text { highlighted } \\
\text { TIC principles are } \\
\text { utilized during goal } \\
\text { setting. The person } \\
\text { and/or family in care } \\
\text { would be able to } \\
\text { recognize that their } \\
\text { care is offered in the } \\
\text { context of a TIC } \\
\text { practice. The } \\
\text { elements of safety, } \\
\text { choice, } \\
\text { collaboration, } \\
\text { trustworthiness, and } \\
\text { empowerment are } \\
\text { highlighted } \\
\text { Individuals are } \\
\text { educated about the } \\
\text { importance of using } \\
\text { outcomes to assess } \\
\text { how treatment is } \\
\text { supporting goals. The } \\
\text { organization should } \\
\text { report on general } \\
\text { outcomes for all } \\
\text { care provided. This } \\
\text { can be } \\
\text { individualized, e.g. } \\
\text { use of SuDS, GAD-7, } \\
\text { PCL-5 }\end{array}$ \\
\hline
\end{tabular}


Trauma-Informed Care Provider Follow-Up Interview Form

SITE NAME:

INTERVIEWEE:

\section{Name}

Name
DATE:

DURATION OF INTERVIEW:
$M M / D D / Y Y Y Y$

XX minutes

Hello,

My name is Mira Snider, and I am a graduate intern at Community Care Behavioral Health Organization. Thank you for agreeing to speak with me today about the Trauma Informed Care Project at your organization. Our conversation today will be used to better understand the long-term effects of the TIC learning collaborative at your specific organization. Please note that this survey will not be used to formally evaluate your performance; rather, it is meant to help us understand the ways that the learning collaborative has affected your organization's use of trauma-informed practices and your firsthand experience as an organization who participated in this initiative. All of your responses today are completely voluntary, and we can end the survey at any time. Do you have any questions before we begin?

[Pause and address questions]

Great. For each of the following questions, I will be taking notes to document your responses. I may ask you to repeat an answer to ensure that I am recording things accurately.

[Start survey on next page]

Section A. Confidence Survey

Before this phone survey, please administer the following question to your staff members and answer the 3 questions below:

How confident are you in providing trauma informed care to the individuals you serve?

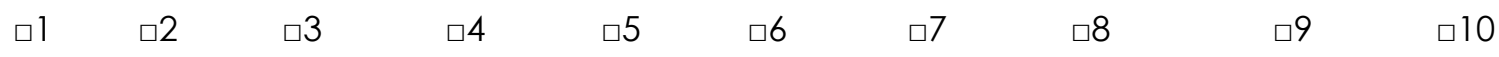

Not at all confident Somewhat confident Extremely confident

1. Number of staff surveyed for confidence:

2. Number of staff who provided ratings of 9 or 10 : 
3. Average response you received:

Section B. Demographic Questions

\begin{tabular}{|c|c|c|}
\hline & FTES & Comments \\
\hline Number of FTEs available: & Ex. 1.5 FTEs & \\
\hline \multicolumn{3}{|l|}{ a. Psychiatry } \\
\hline \multicolumn{3}{|l|}{ b. RN } \\
\hline \multicolumn{3}{|l|}{ c. CRNP } \\
\hline \multicolumn{3}{|l|}{ d. PA } \\
\hline \multicolumn{3}{|l|}{ e. Outpatient therapist } \\
\hline \multicolumn{3}{|l|}{ f. Peer Support } \\
\hline \multicolumn{3}{|l|}{ g. Case Manager } \\
\hline \multicolumn{3}{|l|}{ h. Other: (specify)_ } \\
\hline $\begin{array}{l}\text { Staff education level (est. } \\
\text { percentage of staff per category): }\end{array}$ & $\%$ of staff & Comments \\
\hline \multicolumn{3}{|l|}{ a. High School/GED } \\
\hline \multicolumn{3}{|l|}{ b. Bachelors (BA/BS) } \\
\hline \multicolumn{3}{|l|}{ c. Masters (MS/MA) } \\
\hline \multicolumn{3}{|l|}{ d. Doctorate (PhD/MD) } \\
\hline \multicolumn{3}{|l|}{ e. Other } \\
\hline $\begin{array}{l}\text { Staff roles (est. percentage of staff } \\
\text { per category): }\end{array}$ & $\%$ of staff & Comments \\
\hline a. Clinical & & \\
\hline b. Non-clinical & & \\
\hline
\end{tabular}

Section B. Priority Interview Questions 


\begin{tabular}{|c|c|c|c|c|}
\hline $\begin{array}{l}\text { Please estimate the following for each treatment } \\
\text { modality: }\end{array}$ & TF-CBT & СРТ & DBT & Seeking Safety \\
\hline $\begin{array}{l}\text { a. Number of staff who participated in } \\
\text { training }\end{array}$ & & & & \\
\hline b. Number of staff who completed training & & & & \\
\hline $\begin{array}{l}\text { c. Number of untrained staff remaining at } \\
\text { your organization }\end{array}$ & & & & \\
\hline $\begin{array}{l}\text { d. Number of staff currently using this in their } \\
\text { practice }\end{array}$ & & & & \\
\hline $\begin{array}{l}\text { Please estimate the number of individuals in } \\
\text { service who were screened for trauma symptoms } \\
\text { in the LAST MONTH: }\end{array}$ & \multicolumn{4}{|c|}{$\begin{array}{l}\text { Please describe the types of trauma symptom } \\
\text { screeners that are used at your organization: }\end{array}$} \\
\hline $\begin{array}{l}\text { Please estimate the number of staff who } \\
\text { completed trauma-informed care training in the } \\
\text { LAST MONTH: }\end{array}$ & \multicolumn{4}{|c|}{$\begin{array}{l}\text { Please estimate the total number of staff at } \\
\text { your organization who have been trained in } \\
\text { trauma-informed care: }\end{array}$} \\
\hline $\begin{array}{l}\text { Is staff turnover an issue of concern for your } \\
\text { agency? } \\
\text { Y } \quad \mathrm{N} \quad\end{array}$ & \multicolumn{2}{|c|}{$\begin{array}{l}\text { Estimate the } \\
\text { percentage of } \\
\text { staff retained LAST } \\
\text { MONTH: }\end{array}$} & \multicolumn{2}{|c|}{$\begin{array}{l}\text { Estimate the percentage } \\
\text { of staff retained LAST } \\
\text { YEAR: }\end{array}$} \\
\hline \multicolumn{5}{|l|}{$\begin{array}{l}\text { How has your organization been impacted by } \\
\text { staff turnover? }\end{array}$} \\
\hline \multicolumn{5}{|l|}{$\begin{array}{l}\text { How is your site managing turnover (i.e., what } \\
\text { strategies are being used)? }\end{array}$} \\
\hline $\begin{array}{l}\text { Has staff turnover impacted your ability to deliver } \\
\text { trauma-informed care? }\end{array}$ & \multicolumn{4}{|c|}{$\mathrm{Y} \quad \square \quad \mathrm{N} \square$} \\
\hline \multicolumn{5}{|l|}{ a. If so, how? } \\
\hline \multicolumn{5}{|l|}{ b. What have you done to overcome it? } \\
\hline \multicolumn{5}{|l|}{$\begin{array}{l}\text { How successful has your site been in } \\
\text { implementing trauma symptom screening since } \\
\text { the start of the TIC Learning Collaborative (Sept } \\
\text { 2016)? }\end{array}$} \\
\hline \multicolumn{5}{|l|}{$\begin{array}{l}\text { a. What made it possible to implement } \\
\text { trauma screening? }\end{array}$} \\
\hline \multicolumn{5}{|l|}{$\begin{array}{l}\text { b. What made it difficult to implement } \\
\text { trauma screening? }\end{array}$} \\
\hline \multicolumn{5}{|l|}{$\begin{array}{l}\text { How successful has your site been in } \\
\text { implementing trauma informed care staff } \\
\text { trainings since the TIC Learning Collaborative? }\end{array}$} \\
\hline \multicolumn{5}{|l|}{$\begin{array}{l}\text { a. What made it possible to implement } \\
\text { trainings? }\end{array}$} \\
\hline $\begin{array}{l}\text { b. What made it difficult to implement } \\
\text { trainings? }\end{array}$ & & & & \\
\hline
\end{tabular}


Section D. Non-Priority Interview Questions (complete if there is sufficient time)

\begin{tabular}{|c|c|}
\hline $\begin{array}{l}\text { Has your site continued to use trauma-informed supervision } \\
\text { approaches? }\end{array}$ & $\mathrm{Y} \quad \square \quad \mathrm{N} \square$ \\
\hline $\begin{array}{l}\text { a. What has this looked like at your agency over the } \\
\text { past } 3 \text { years? }\end{array}$ & \\
\hline b. How is this going for your agency? & \\
\hline $\begin{array}{l}\text { c. What changes would you like to see pertaining to } \\
\text { supervision? }\end{array}$ & \\
\hline $\begin{array}{l}\text { To what extent is your agency networking and } \\
\text { collaborating with other organizations regarding the use of } \\
\text { trauma-informed care? }\end{array}$ & \\
\hline $\begin{array}{l}\text { a. What has this collaboration looked like over the } \\
\text { past } 3 \text { years? }\end{array}$ & \\
\hline $\begin{array}{l}\text { b. Have referrals at this agency become meaningful } \\
\text { and appropriate? }\end{array}$ & \\
\hline $\begin{array}{l}\text { c. Have interactions outside of your organization } \\
\text { helped with quality of referrals or with providing } \\
\text { more appropriate referrals? }\end{array}$ & \\
\hline $\begin{array}{l}\text { At your agency, do you feel as though you have been } \\
\text { able to make changes such that the whole organizational } \\
\text { culture has changed? }\end{array}$ & \\
\hline $\begin{array}{l}\text { a. Describe ways that you feel like trauma-informed } \\
\text { care has been sustained by the organization over } \\
\text { the past } 3 \text { years. }\end{array}$ & \\
\hline $\begin{array}{l}\text { b. Describe any systemic issues you have faced while } \\
\text { implementing trauma-informed care (e.g., } \\
\text { screening, trainings, referrals). }\end{array}$ & \\
\hline $\begin{array}{l}\text { Did your site initially implement trauma-informed care with } \\
\text { adults or children? }\end{array}$ & \\
\hline $\begin{array}{l}\text { a. Have you expanded the implementation of } \\
\text { trauma-informed care to other populations over the } \\
\text { past } 3 \text { years? }\end{array}$ & \\
\hline
\end{tabular}

\begin{tabular}{|l|l|l|l|l|}
\hline Please rate the following: & $\begin{array}{l}\text { Definitely } \\
\text { False }\end{array}$ & $\begin{array}{l}\text { Somewhat } \\
\text { False }\end{array}$ & $\begin{array}{l}\text { Somewhat } \\
\text { True }\end{array}$ & $\begin{array}{l}\text { Definitely } \\
\text { True }\end{array}$ \\
\hline $\begin{array}{l}\text { 11. New ideas are readily accepted at this } \\
\text { agency }\end{array}$ & $\square$ & $\square$ & $\square$ & $\square$ \\
\hline $\begin{array}{l}\text { 12. This agency is quick to respond when changes } \\
\text { need to be made }\end{array}$ & $\square$ & $\square$ & $\square$ & $\square$ \\
\hline $\begin{array}{l}\text { 13. Management at this agency are quick to spot } \\
\text { the need to do things differently }\end{array}$ & $\square$ & $\square$ & $\square$ & $\square$ \\
\hline $\begin{array}{l}\text { 14. This agency is very flexible; it can quickly } \\
\text { change procedures to meet new conditions and } \\
\text { solve problems as they arise }\end{array}$ & $\square$ & $\square$ & $\square$ & $\square$ \\
\hline $\begin{array}{l}\text { 15. Assistance in developing new ideas is readily } \\
\text { available at this agency }\end{array}$ & $\square$ & $\square$ & $\square$ & $\square$ \\
\hline $\begin{array}{l}\text { 16. People in this agency are always searching for } \\
\text { new ways of looking at problems }\end{array}$ & $\square$ & $\square$ & $\square$ & $\square$ \\
\hline
\end{tabular}




\begin{tabular}{|l|l|l|l|l|}
\hline $\begin{array}{l}\text { 17. Supervision practices at this agency are } \\
\text { trauma-informed }\end{array}$ & $\square$ & $\square$ & $\square$ & $\square$ \\
\hline $\begin{array}{l}\text { 18. Debriefing for trauma cases is provided to staff } \\
\text { when needed. }\end{array}$ & $\square$ & $\square$ & $\square$ & $\square$ \\
\hline $\begin{array}{l}\text { 19. Staff wellness programs are provided } \\
\text { 20. The workplace culture at this agency is } \\
\text { trauma-informed }\end{array}$ & $\square$ & $\square$ & $\square$ & $\square$ \\
\hline
\end{tabular}




\section{Appendix C. Diagnostic Codes to Identify Trauma-Related Services}

\begin{tabular}{lll}
\hline $\begin{array}{l}\text { ICD-10 } \\
\text { Code }\end{array}$ & $\begin{array}{l}\text { DSM-5 } \\
\text { Code }\end{array}$ & Name \\
\hline F43.0 & 308.3 & Acute stress disorder \\
F43.10 & 309.81 & $\begin{array}{l}\text { Post-traumatic stress disorder, unspecified } \\
\text { Post-traumatic stress disorder, acute }\end{array}$ \\
F43.11 & & Post-traumatic stress disorder, chronic \\
F43.12 & & Adjustment disorder, unspecified \\
F43.20 & 309.9 & Adjustment disorder with depressed mood \\
F43.21 & 309.0 & Adjustment disorder with anxiety \\
F43.22 & 309.24 & Adjustment disorder with mixed anxiety and depressed mood \\
F43.23 & 309.28 & Adjustment disorder with disturbance of conduct \\
F43.24 & 309.3 & Adjustment disorder with mixed disturbance of emotions and conduct \\
F43.25 & 309.4 & Adjustment disorder with other symptoms \\
F43.29 & & Other specified trauma and stressor-related disorder \\
F43.8 & 309.89 & Unspecified trauma and stressor-related disorder \\
F43.9 & 309.9 & Reactive attachment disorder of childhood \\
F94.1 & 313.89 & Disinhibited attachment disorder of childhood \\
F94.2 & 313.89 &
\end{tabular}

